\title{
The negative priming paradigm: An update and implications for selective attention
}

\author{
Christian Frings $^{1} \cdot$ Katja Kerstin Schneider $^{1}$ - Elaine Fox ${ }^{2}$
}

Published online: 28 April 2015

(C) Psychonomic Society, Inc. 2015

\begin{abstract}
Negative Priming (NP) is an influential paradigm in cognitive psychology that was originally developed to measure attentional selection. Yet, up to the mid-1990s, a large number of experimental reports questioned whether the NP effect is based on attentional inhibition and/or episodic retrieval processes. In this review, we summarize findings since the mid1990s and discuss new and old theoretical approaches to Negative Priming. We conclude that more than one process contributes to NP and that future research should analyze the conditions under which a particular process contributes to NP. Moreover, we argue that the paradigm - although it does not measure a single cognitive process alone - is still a useful tool for understanding selection in cognition. In fact, it might be a virtue of the paradigm that several cognitive processes work here together as selection in nonexperimental contexts is surely a multidimensional process. From this perspective, research on NP is relevant for all research fields analyzing selection. We therefore close our review by discussing the implications of the new evidence on NP for theories of selective attention.
\end{abstract}

Keywords Negative priming · Attention · Selective attention $\cdot$ Memory

If a to-be-ignored stimulus (distractor) from a prime display becomes the to-be-selected stimulus (target) in the subsequent probe display, then a person's response to this target is impaired

Christian Frings

chfrings@uni-trier.de

Cognitive Psychology, University of Trier, 54286 Trier, Germany

2 Oxford Centre for Emotions and Affective Neuroscience, Department of Experimental Psychology, University of Oxford, 9 South Parks Road, Oxford OX1 3UD, England in terms of the latency and/or accuracy of their response. Neill (1977) was the first to use this kind of task with discrete prime and probe displays following some pioneering work by Dalrymple-Alford and Budayr (1966), and the phenomenon was subsequently labeled negative priming (NP; Tipper, 1985). Since the original observation of the NP effect in 1966, more than 500 papers have been published and NP remains a prevailing paradigm today. One reason for the popularity of NP is that the paradigm is often assumed to provide a valid assessment of attentional selection, especially selective inhibition of distracting information. In the last 40 years, however, there has been serious debate among cognitive psychologists as to whether NP effects are primarily based on inhibition or retrieval mechanisms. In contrast, psychologists from other research fields typically use this paradigm as an index of a participants' ability to ignore distracting information without too much concern regarding the underlying processes.

In the present review, we ask and answer several questions that might be of interest to a wide range of researchers interested in the NP phenomenon. A number of comprehensive reviews on NP were published in the mid 1990s (Fox, 1995; May, Kane, \& Hasher, 1995; Neill \& Valdes, 1996), but since then several new theories have been proposed and much new data have been presented. While some partial reviews have been published more recently (Mayr \& Buchner, 2007; Neill, 2007; Tipper, 2001), we felt the time was right for an update to the general reviews from 1995-1996. We summarize results and papers that have appeared after 1995, we present new and already influential theories on NP, and we discuss some general questions about why research on and with the NP paradigm is still of wide interest. The general idea is to provide researchers interested in the NP phenomenon an overview of developments in the past 20 years or so. In Table 1 we highlight the key messages on NP since the mid-1990s that we lay out in detail in our review below. 
Table 1 Key messages on NP since the mid-1990s

Key messages on Negative Priming

The temporal discrimination theory has been suggested as a new explanation of NP. Central to this theory is the assumption that an attentional system differentiates between stimuli whose response is already known (and can be retrieved from memory) and stimuli where a response has to be newly computed. In the ignored repetition condition, interference results as a consequence of both new and old information being present.

The stimulus response retrieval theory is another new approach and makes the assumption that the prime episode is stored as an event-file in memory. This event-file includes every feature of the prime episode as well as the specific response that is required. In an IR trial, the probe display leads to a retrieval of the prime response; if the prime response is not identical to the presently required response, interference causes a slowing in reaction time.

The theory of transfer-(in)appropriate processing can be seen as a variant of the episodic retrieval theory and postulates that a stimulus reinstates processing operations similar to those applied to it in the past. This leads to interference in the ignored repetition, since operations linked to the probe target (previously the prime distractor) are inappropriate for current task demands. The TAP/TIP theory can be seen as an "update" of the original episodic retrieval theory.

Negative priming tasks are not ideal tools to measure cognitive inhibition exclusively, since retrieval processes also contribute to the NP effect. This is due to the sequential character of NP tasks, which are composed of the conjoined prime and probe trials. Furthermore, the reliability of NP performance is very low.

Contrary to earlier views, NP is not generally reduced in subjects diagnosed with psychiatric disorders. Nevertheless, there are clear indications that schizophrenia leads to impairments in NP. Other disorders were also associated with anomalous NP; yet, these findings are still preliminary.

Differences in lifestyle (stress, alcohol consumption, sleep-deprivation, physical activity) have been linked to enlarged or reduced NP. These findings are preliminary due to the limited number of studies.

Age has not been identified as a factor that influences NP. Neither children nor older adults generally display NP deficits, regardless of the specific nature of the task. This finding contrasts with previous theories, which assumed that NP was impaired in children and older adults.

There is a strong indication for an involvement of the frontal lobe especially the right dorsolateral prefrontal cortex - in the processing of NP interference. So far, there is no consensus which brain regions are distinctively activated in identity or spatial NP tasks.

While the ERP correlates of negative priming are to some extent inconsistent, the early sensory aspects of stimulus processing - as assessed by $\mathrm{P} 1$ and $\mathrm{N} 1$ components - do seem to be modified by the ignored repetition condition. This has been found mainly in spatial NP variants, whereas variations in the $\mathrm{N} 2$ and $\mathrm{P} 3$ components as well as the LPC have been observed in several identity tasks.

NP can be observed even in the absence of probe distractors. If algorithmic probe processing is slow (e.g., due to degraded targets), retrieval process then have a chance to have an effect even without probe distractors present.

Negative priming effects are not limited to the visual domain and have been observed for auditory, tactile and olfactory stimuli as well. In addition, negative priming can also be induced in cross modal tasks and in tasks that utilize bilingual stimuli. While these findings indicate that NP is a modality-independent process, other findings suggest that $\mathrm{NP}$ is not completely equivalent in different modalities and should be further studied for its unique, modality-contingent variations.

Location NP should be separated from identity NP. Various studies suggest that partially different mechanisms contribute to these types of NP.

NP task (basics). Since the first theory on NP was introduced (i.e. response suppression, cf. Neill, 1977) a wide array of different tasks have been developed. A full portrayal of all subtypes will not be accomplishable in this review, but we describe the main types and present one of the standard NP paradigms, a variant of the letter naming task (Neill, 1997) as well as a location task variant. The typical trial events of this task are depicted in Fig. 1 and show the basic principle of the paradigm. An NP trial consists of two consecutive displays, termed prime display and probe display. Both displays contain a target that requires a response, and at least one stimulus that is irrelevant to the task at hand and requires no response, the so-termed distractor. In our exemplary identity NP task (see Fig. 1, left panel), the subject is asked to identify the central of three letters. The central letter is the target in both prime and probe, while the flanking letters serve as the distractor stimuli. There are three standard conditions: prime and probe stimuli can be completely unrelated (control condition), the prime target can be repeated in the probe (attended repetition; AR) and the prime distractor can serve as probe target (ignored repetition; IR). While attended repetition results in positive priming and causes a faster reaction as compared to control trials (facilitation), the ignored repetition creates an interference that is reflected in slower reaction times as compared to control trials. The NP effect is the difference between ignored repetition and control trials (usually in regard to mean reaction times, though error rates are often taken into account as well). By now, NP tasks have been developed for many different stimuli and are not limited to the visual domain (see below).

A coarse-grained categorization of NP tasks concerns the level at which NP takes place. In identity NP participants respond to the identity of the target stimulus. This is not limited to classifying letters via key presses but can also involve naming pictures overlapping each other (Tipper, 1985). In contrast, in spatial or location NP, the interference is created by the stimulus position rather than its identity. In an IR trial, the probe target is presented at the location of the prime distractor and thereby causes the typical NP interference (see, e.g., Tipper, Brehaut, \& Driver, 1990).

NP can also rely on the semantic similarity between the prime distractor and the probe target (e.g., Tipper \& Driver, 1988). For example, the prime distractor cat can be followed by the probe target $d o g$ - the semantic relatedness between both words is driving the NP interference. These semantic NP effects are usually smaller than effects obtained from identity or spatial tasks (Fox, 1995) and a sizeable portion of studies also report a failure to replicate semantic NP. This has led to a debate in the last few years concerning whether semantic NP actually exists (Chiappe \& MacLeod, 1995; MacLeod, Chiappe, \& Fox, 2002).

\section{Main conclusions drawn in the 1995-1996 reviews}

NP theories have typically differentiated between inhibition(Houghton \& Tipper, 1994; Tipper, 1985) and retrieval-based accounts (Neill, Valdes, Terry, \& Gorfein, 1992). The traditional inhibition theory assumed that the abstract 

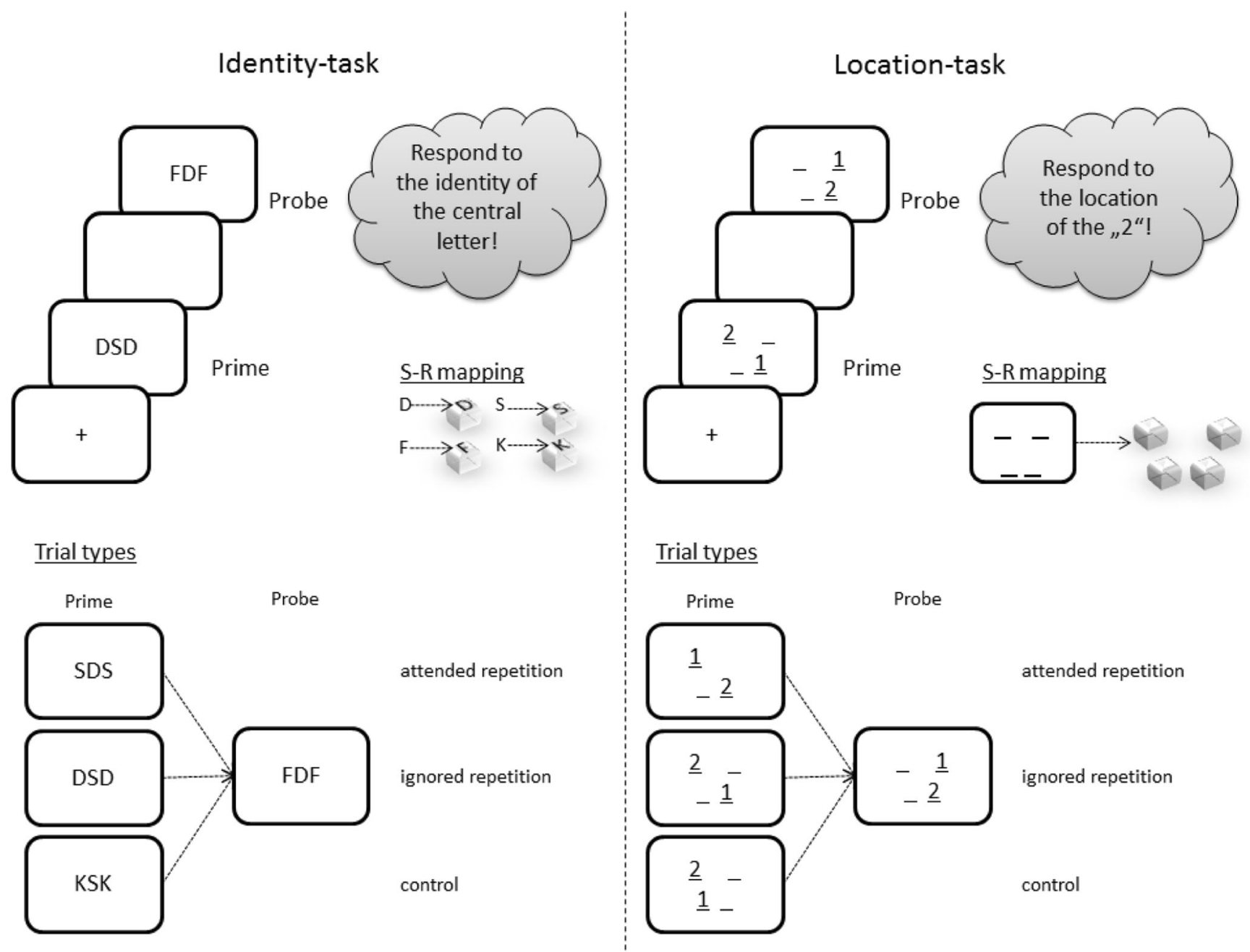

Fig. 1 The typical sequence of events and trial types in a letter identification task (left panel) and a location-task (right panel). See text for further explanations.

representation of the distractor stimulus is actively suppressed by mechanisms of selective attention during the processing of the prime episode and that this inhibition persists until the presentation of the next display. Thus, when the ignored distractor from the prime trial becomes the probe target (the ignored-repetition condition), the recently inhibited representation has to be activated in order for the participant to respond, and hence NP occurs.

The finding, that NP needed time to develop, was interpreted as support for the inhibition theory; that is, if the probe was presented directly after the prime, inhibition did not have enough time to develop and as a result NP diminished (e.g., Allport, Tipper, \& Chmiel, 1985). In addition, the relation between selection difficulty on the prime and NP was interpreted in terms of inhibition (the more difficult the prime selection the larger the NP effect; e.g., Fox, 1994; Milliken, Tipper, \& Weaver, 1994). Finally, diminished NP effects in the elderly were sometimes interpreted in terms of the "loss of inhibition" hypothesis (e.g., Hasher, Stoltzfus, Zacks, \& Rypma, 1991).
By contrast, retrieval theories argued that NP is caused by the fact that perceiving a target activates memory traces associated with a previous processing episode containing that particular stimulus. In the ignored-repetition condition, the last memory trace of the current target stimulus contains information indicating "was ignored" or "did-not-respond," and it is this information that interferes with a person's ability to respond quickly and accurately to the probe target.

Several findings pointed to episodic retrieval processes, for instance, the persistence of NP depended on the ease of discriminability of the prime episode (Neill et al., 1992). Another finding was the dependence of NP on the presence of probe distractors that could possibly be explained in term of reduced retrieval due to mismatches between probes and primes (e.g., Fox \& De Fockert, 1998; Lowe, 1979; Moore, 1994). The absence of NP effects when there is no distractor on the probe display seems difficult to explain from a traditional inhibition perspective.

Yet, already in the mid-1990s it seemed that both accounts were well supported by the empirical literature (Fox, 1995), 
and nowadays most researchers agree that both inhibitory mechanisms and retrieval processes likely contribute to NP (see, e.g., Kane, May, Hasher, Rahhal, \& Stoltzfus, 1997; Tipper, 2001; Neill, 2007). However, at least three new approaches have been suggested more recently - namely, the temporal discrimination theory, transfer-(in)appropriate processing, and what we call the stimulus response retrieval theory.

\section{What new explanations/theories for the NP effect have been suggested?}

The temporal discrimination theory Milliken and colleagues (Milliken \& Joordens, 1996; Milliken, Joordens, Merikle, \& Seiffert, 1998) suggested an alternative explanation for the NP effect. At the core of their theory is an attention system that codes whether a response to a stimulus is already known and can be directly retrieved from memory, or whether a response to a stimulus is unknown and must be "computed" in a controlled mode of processing. Furthermore, it is assumed that the time needed for the attention system to decide whether a display is old (and a response is already known) or new (and a response is yet unknown) is a nonmonotonic function of the match between the prime display and the probe display. In particular, if the target is repeated between prime and probe displays, then the attention system should quickly recognize the probe target as "old" and the response from the last trial is retrieved from memory. If nothing is repeated between prime and probe displays - the control condition - then the attention system rather quickly determines the probe target as "new," and a corresponding response is computed. Finally, if the prime distractor becomes the target in the probe display, the probe display contains both old and new information and this ambiguity is assumed to slow down the decision process. Milliken and colleagues attribute NP to this ambiguity in the ignored-repetition condition.

The temporal-discrimination theory receives support from the finding that NP is also observed when a single, irrelevant prime stimulus precedes the probe episode. In their experiments, Milliken et al. (1998) briefly flashed single prime words, which were preceded and followed by a mask before presenting the probe episode containing two words. Participants task was to focus attention on the masks and then to name the target word from the probe episode, which was designated by color. When the prime and the target word were identical, significant NP was observed. The authors interpreted this finding as evidence against the view that "selecting against" a prime distractor is a necessary condition for NP to occur (see also Joordens, Betancourt, \& Spalek, 2006). Yet, these findings are consistent with the temporaldiscrimination theory because the brief presentation of prime words that are related to the subsequent target words should produce ambiguity regarding the decision of whether the probe target is old or new. The NP effect after ignored, single distractor prime-displays has been replicated by different laboratories in the meanwhile (e.g., Healy \& Burt, 2003; Neill \& Kahan, 1999). Furthermore it has been demonstrated that unawareness of the masked primes is a precondition for observing NP with these stimuli (Frings \& Wentura, 2005; Healy \& Burt, 2003), which supports the view that ambiguity is critical. In addition, the time-course of masked NP seems to be in line with the temporal discrimination theory. In particular, the more time that elapses between the prime and the probe display the more unreliable is the decision process as to whether the target is old or new. Importantly, a simple decay function (less NP with increasing time interval between masked prime distractor and the probe display) is predicted by the temporal discrimination theory and has been found (Frings \& Eder, 2009). It must be noted, that this time function also fits to other accounts of the NP phenomenon.

The idea that the human brain tries to disentangle two consecutive events that are presented in a rather fast fashion holds for many other paradigms, such as the semantic priming paradigm as well (for reviews, see Lucas, 2000; McNamara \& Holbrook, 2003; Neely, 1991). Kahan (2000) argued that participants try to clarify masked primes by using the information the target stimulus provides. In the case of related prime-target pairs, this matching process is quite hard because it is difficult to disentangle the prime episode from the target episode. Thus, it is fair to assume that some kind of temporal discrimination process does take place in most sequence effects. In addition, NP from masked distractors is a reliable empirical phenomenon, and every NP theory must handle this evidence. Whether a complete new account should be derived from this evidence is, however, questionable. For instance, if one assumes that participants ignore single prime distractors (as they are implicitly told to do) a retrieval account might also explain most of the results on which the temporal discrimination idea was born. Thus, it may also be possible and more parsimonious to integrate the temporal discrimination process into an enhanced retrieval account (Frings \& Wühr, 2007).

The stimulus response retrieval theory This theory may be seen as a variant of the episodic retrieval theory. However, for reasons we explain below, we would argue that this theory is in fact a new approach to NP in general. At its core this theory holds that the whole prime episode (containing the prime target, the prime distractor, and the response to the target) is stored in memory and that the whole episode is automatically retrieved if a known stimulus is encountered again. Thus, the theory applies the idea of "event files" to the NP paradigm. In particular, Hommel $(1998,2004)$ suggested that stimulusinformation and response-information become integrated into "event files." Thus, presenting a stimulus a second time will automatically activate the formerly executed response to this 
stimulus and therefore facilitate performance if the current response is identical to the encoded response. Yet, if the current response is different from the retrieved response, interference will cause slowing in reaction time. It is important to note that such a binding of stimulus information and response is assumed to occur incidentally without any form of relation between a stimulus and a response other than temporal contiguity. For explaining NP, it has been suggested that distractor stimuli are also bound into an event file (Mayr \& Buchner, 2006; Rothermund, Wentura, \& De Houwer, 2005). Thus, repeating a distractor retrieves the last episode containing the distractor including the response to the target that was encountered together with this distractor. In turn, retrieving a distractor impairs performance if the response (to the former target) is incompatible to the actually to-be-executed response. For the ignored repetition condition, the retrieved prime response is always incompatible as long as the prime display did not comprise a compatible target-distractor pair. The stimulus response retrieval theory gains evidence from experiments in which the relation of the prime response and the response that was required in the probe was systematically varied by using a task switch between prime and probe (Rothermund et al., 2005). In the ignored repetition condition, for instance, responding is delayed if different responses are required in the prime and probe, whereas repeating the prime distractor as the probe target facilitates responding if the same response is required in the prime and in the probe. Frings, Rothermund, and Wentura (2007) showed this interaction for distractor-todistractor repetitions; when the response repeated between prime and probe distractor, repetitions caused benefits, whereas they caused delays (cost effects) when the response changed. In addition, Mayr and Buchner (2006) showed that the probability for repeating the (wrong) prime response to the probe display was significantly higher in ignored repetition trials as compared to control trials (i.e., participants repeated a response to a stimulus that was not presented in the current probe display at all). This is exactly what the stimulus response retrieval theory predicts because the former prime distractor (and now the probe target) retrieves the response given to the former prime target.

In addition, Mayr, Buchner, and Dentale (2009) showed that the prime response must be executed in order to be encoded in the prime episode and in turn can be retrieved in ignored repetition trials. By applying a go/no-go design to a NP paradigm, they found erroneously repeated prime responses only in ignored repetition trials in the go condition, irrespective of the fact that in the reaction times the NP effect was there in both go and no-go conditions. Gibbons and Stahl (2008) made a somewhat related observation by using a lateralized readiness potential (LRP) measure in a NP task. When the probe target retrieved a prime episode containing the same response hand (in the ignored repetition condition) the probe response hand was pre-activated as compared to a control condition whereas if the probe target retrieved a prime episode containing the other response hand the probe response hand activation was delayed. Yet, irrespective of response shifts between prime and probe NP effects were always observed. In sum, the results from Mayr et al. (2009a, b) as well as from Gibbons and Stahl (2008) suggest that the stimulus response retrieval process cannot be the only source of NP effects. In this regard, the results of Milliken et al. (1998; i.e., single distractor primes that were ignored but not responded to cause the NP effect) cannot easily be incorporated into the stimulus-response retrieval theory.

The stimulus response retrieval account of NP can be integrated into a broader theoretical framework encapsulated by the theory of event coding (Hommel, 2004; Hommel, Müsseler, Aschersleben, \& Prinz, 2001). This might lead to a better understanding of the different cognitive functions that are typically at work in experimental tasks in cognitive psychology; the NP paradigm might evolve as the task that is the best suited to analyze distractor-response-bindings, but at the same time this framework does not exclude the impact of other cognitive functions (like inhibition, for example). There is an important, theoretical point to make here. The two major traditional approaches to NP (i.e., inhibition and episodic retrieval theory) both assume some kind of selection in the prime display (Tipper, 2001). In particular, the inhibition theory assumes that the prime target is activated whereas the prime distractor is inhibited; while the episodic retrieval theory also assumes (at least implicitly) a separation process: when the distractor is encoded with a do-not-respond tag, it must be separated from the target - respond - representation. In sharp contrast, the stimulus response retrieval theory does not assume that any kind of selection occurs at the prime display - instead it is argued that the whole episode is encoded. Thus, the stimulus response retrieval theory is distinct from both inhibition and episodic retrieval accounts as it does not assume any kind of selective encoding and storing.

Transfer-(in)appropriate processing Neill and Mathis (1998) were the first who suggested explaining NP in terms of transfer appropriate processing (TAP) or transfer inappropriate processing (TIP); this approach can also be seen as a modified version of the original episodic retrieval theory (cf. Neill, 2007). TIP/TAP means that a stimulus reinstates processing operations similar to those applied to it (or a similar stimulus) in the past (cf. Kolers, 1976; Morris, Bransford, \& Franks, 1977). Originally, this idea was used to explain performance in different memory tasks. For example, when the learning/encoding phase tapped conceptual (perceptual) processing, participants performance was increased when the recall/retrieval phase also requested conceptual (perceptual) processing irrespective of whether implicit or explicit memory processes were analyzed (e.g., Blaxton, 1989; Roediger, 1990). Yet, the TAP principle can also be broadened to explain 
effects in various priming paradigms, including the NP paradigm (Leboe, Whittlesea, \& Milliken, 2005). In the particular case of NP, the processes reinstated with the processing of a probe target that was a former prime distractor are considered inappropriate for computing the current demanded response; that is, a distractor in an ignored repetition trial might activate its cognitive representation but the processes that were encoded with this representation are now inappropriate and in turn might cause interference in computing the target response.

The TIP principle in NP is evidenced by experiments of MacDonald, Joordens, and Seergobin (1999), who used a comparison task variant of NP. In particular, participants were required to name the larger one of two presented animals in both the prime and the probe. Thus, the not-chosen prime animal (the distractor) was fully analyzed and not ignored in fact, participants could compute the correct answer only after making a comparison between the prime target and prime distractor. However, repeating a relatively large prime distractor animal as a relatively small probe target animal led to reaction time costs. The TIP approach explains this finding by assuming that when encoding and retrieval differ (e.g., the animal was relatively small in one and relatively large in the other instance) prior processing interferes with the current demands of the probe task. A similar observation was made by Wood and Milliken (1998) who presented participants new nonsense shapes with deep or shallow encoding instructions. When participants discriminated shapes in a same-different task, reaction times for older shapes were slower - in support of the TIP principle because retrieved inappropriate processing interfered with the demand of the new task. In addition, Leboe et al. (2005) varied the similarity of prime and probe display along the dimensions of color, lexical status, and orthographic structure and participants had to made color or lexical decision responses. When prime processing was appropriate for the probe task, contextual similarity on color or orthography speeded responses (which evidenced TAP like processes). In contrast, when processes engaged during prime processing were inappropriate for the demands of the probe, similarity slowed response times (which evidenced TIP like processes); yet, these effects were somewhat weaker as compared to the TAP-like processes. Finally, it should be noted that many observations that served as evidence for episodic retrieval - for example, the perceptual similarity between the prime and the probe (e.g. Neill, 1997; Fox \& De Fockert, 1998; but see Wong, 2000) - can also be interpreted as evidence for the TAP/TIP approach on NP (although there are findings that cannot be explained by TAP/TIP; for example, Buckolz, Goldfarb, \& Khan, 2004; Shiu \& Kornblum, 1996).

The TAP/TIP approach embeds NP results into a broader theoretical framework that links many different tasks and paradigms. The assumption of a do-not-respond tag as suggested in the episodic retrieval theory seems implausible (e.g., for masked distractors) whereas the TIP approach can more easily explain such results. Simultaneously, the TIP approach does not need much more assumptions than the episodic retrieval approach so that this enhanced theory can explain much of the empirical data in NP.

\section{Should we use the NP effect for measuring inhibition?}

The two questions of (a) how to measure inhibition and (b) how to measure individual differences in inhibition are frequently confounded. The answer to the first question is relatively straightforward. If one is interested in pure cognitive inhibition (for a working definition, see, e.g., MacLeod, 2007) and no other process, the NP paradigm is - with respect to the evidence from the last 20 years - not the ideal task. This is because both inhibition and retrieval processes almost certainly contribute to the NP effect (Fox, 1995; Kane et al., 1997; Neill, 2007; Tipper, 2001). There are two potentially more appropriate measures of pure inhibition that do not seem to be confounded by retrieval processes. First, U. Mayr and colleagues (e.g., U. Mayr, 2007; Mayr \& Keele, 2000) used a task-switching paradigm and observed reaction time costs in a particular task sequence: When Task A was repeated, but with an intervening, different Task B (i.e., in an ABA sequence), performance in the second instance of Task A decreased compared to a control condition in which $\mathrm{A}$ was not repeated (i.e., CBA sequence). This effect is called the lag-2 repetition effect. In a nutshell, this effect demonstrates that participants inhibit a task set when the task changed (from A to B). If one assumes that inhibition decays relatively slowly, then the results reflect the fact that task set $\mathrm{A}$ is still inhibited when the task changes back from B to A. Thus, this lag-2 repetition paradigm is considered to be purer index of cognitive inhibition when compared to NP (Mayr, 2007).

Second, Wühr and Frings $(2008,2009)$ suggested a variant of the Stroop task in order to measure object-based inhibition. They argued that a critical problem for measuring pure inhibition with NP paradigms is the sequential nature of the task that always opens the door for influences of retrieval processes triggered by the probe. They suggested that the interference from an incompatible Stroop word in a color-naming task can indirectly show whether the object in which the word is presented was inhibited. Specifically, Stroop interference from incompatible color-words was larger when these words were presented in the background as compared to trials in which these words were presented in an irrelevant object; note that influences of spatial attention were controlled for. The difference in Stroop interference from words in the background and words in the irrelevant object taps object-based inhibition in the current trial.

To assess pure inhibition of abstract rules or objects then, these tasks (Mayr, 2007; Wühr \& Frings, 2008, 2009) may be 
preferable to the NP paradigm. This does not imply, of course, that the NP paradigm is not useful if one is interested in measuring the ability to ignore distracting information. Likewise, we are not claiming that the NP task does not partially tap inhibitory processes (see below). In sum, while NP may not be the best experimental index to separately tap inhibition or retrieval processes (cf. Mayr, 2007; Wühr \& Frings, 2008), it remains an important tool with which to investigate the mechanisms of selection that are present in the human cognitive system (Neill, 2007).

\section{Which variables can explain individual differences in NP?}

It seems unproblematic to use the NP paradigm for measuring individual differences in ignoring or processing distracting information - at least when one assumes that the interindividual variance in the NP effect reflects individual differences in the ability to ignore distracting information and does not imply differences in inhibition and/or episodic retrieval (Fox, 1995; Frings, 2008). Several studies have reported correlations between individual NP effects and other measures like a questionnaire or self-reported behavior suggesting that the NP effect can tap individual differences. From a methodical perspective, however, the reliability of the NP paradigm needs to be considered. Friedman and Miyake (2004) reported very low reliability of $r=.10$ and $r=.13$, whereas Titz and colleagues (2003) reported reliabilities between values of $r=$ .02 and $r=.34$. Given these reliabilities it seems clear that the NP paradigm (or a variant) is not appropriate for diagnostic purposes. Nevertheless, in spite of these measurement problems the NP paradigm has been widely used to correlate the ability to ignore distractors and other subjective measures. In the following we reexamine NP-related differences in relation to age, psychological disorders, and distractedness in everyday life as well as discussing other fields of individual differences that have been researched since the earlier reviews (Fox, 1995; May et al, 1995). Table 2 gives a summary of the findings.

Disorders and diseases. NP has been studied in participants with cognitive impairments and deficits, most often those with psychiatric disorders. Difficulties arise with the sample characteristics, as severity of symptoms, comorbidity and medication status differ within groups of patients. In addition, different subtypes of a disorder also need to be considered when comparing studies.

To date, schizophrenia is the disorder that has been researched the most in relation to NP. Schizophrenia is defined by disorganized thinking and speech patterns (World Health Organization, 2013). Schizophrenic patients have, by and large, difficulty in distinguishing between relevant and irrelevant stimuli very well (Elvevag \& Goldberg, 2000; Oltmanns, Weintraub, Stone, \& Neale, 1978) which - in everyday life - means that they cannot select well between stimuli that are important to their behavioral goals and stimuli that are not. Given this impairment, it can be expected that schizophrenic patients show diminished NP. Fox (1995) cited exactly such differences in schizophrenic participants as well as in students with high scores in schizophrenic-like behavior (Beech, Baylis, Smithson, \& Claridge, 1989; Beech \& Claridge, 1987; Beech, McManus, Baylis, Tipper, \& Agar, 1991; Beech, Powell, McWilliam \& Claridge, 1989). May and colleagues (1995) also came to the conclusion that schizophrenic patients and participants with schizophrenic tendencies exhibit less NP or even no NP at all. After nearly two decades of further research, has the opinion on the link between NP and schizophrenia changed?

Schizophrenic and schizotypal patients typically do show reduced levels of NP (or no NP at all) in spatial and identity tasks; in some cases, this seemed to be dependent on the severity of positive symptomatology (Fuller, Frith, \& Jahanshahi, 2000; Hoenig, Hochrein , Müller, \& Wagner, 2002; Laplante, Everett, \& Thomas, 1992; MacQueen, Galway, Goldberg, \& Tipper, 2003; Moritz, Mass, \& Junk, 1998; Park, Lenzenweger, Püschel, \& Holzman, 1996; Sturgill \& Ferraro, 1997; Ungar et al., 2010; Watson \& Tipper, 1997; Zimmermann et al., 2006). However, these findings are not unanimous. Intact NP has been reported several times for various tasks (Hoenig et al., 2002; Moritz \& Andresen, 2004; Zabal \& Buchner, 2006). Park and colleagues (1996) noted regular spatial NP in chronic outpatients, but no NP in acutely psychotic inpatients. Interestingly, deficits in NP were associated with the length (and masking) of stimulus presentation and with the length of response stimulus intervals (Moritz et al., 2001; Salo et al., 2002) prompting Moritz and colleagues to suggest that reduced NP may be due to perceptual deficits rather than deficits in inhibition. This assumption is difficult to maintain, however, since reduced NP has been reported in studies with large RSIs (Park et al., 1996; Sturgill \& Ferraro, 1997; Zimmermann et al., 2006) and with long or response-dependent stimulus representation (Fuller et al., 2000; MacQueen et al., 2003; Park et al., 1996; Sturgill \& Ferraro, 1997).

MacQueen and colleagues (2003) noted an association between clozapine (an antagonist for dopamine and other transmitters) and the magnitude of the NP effect. Patients treated with clozapine displayed greater levels of NP than patients treated with typical antipsychotic drugs. This corresponds to the finding that chlorpromazine (a dopamine antagonist as well) was associated with elevated NP effects in healthy participants (Beech, Powell, McWilliam, \& Claridge, 1990). Minas and Park (2007) concluded that NP effects are diminished or abolished in schizophrenic patients, both for spatial and identity tasks. They pointed out that this association is strongest in the presence of positive schizophrenic 
Table 2 Individual differences in negative priming, key findings

Individual differences in Negative Priming

Disorders and diseases

Schizophrenia, schizotypy

Alzheimer's disease, eating disorder

Major depression, dysphoria

Parkinson's disease, OCD, ADHD,

Tourette's syndrome

Differences in lifestyle

Sleep-deprivation, stress, physical activity

Alcohol

Nicotine

Effect of age

Children

Older adults
Reduced or abolished NP, especially in the presence of positive symptomatology, acute psychosis, high severity of symptoms and/or lacking medication (Fuller, Frith, \& Jahanshahi, 2000; Hoenig, Hochrein, Müller, \& Wagner, 2002; Laplante, Everett, \& Thomas, 1992; MacQueen, Galway, Goldberg, \& Tipper, 2003; Minas \& Park, 2007; Moritz \& Andresen, 2004; Moritz et al. 2001; Moritz, Mass, \& Junk, 1998; Park, Lenzenweger, Püschel, \& Holzman, 1996; Salo, Henik, Nordahl \& Robertson, 2002; Sturgill \& Ferraro, 1997; Ungar, Nestor, Niznikiewicz, Wible, \& Kubicki, 2010; Watson \& Tipper, 1997; Zabal \& Buchner, 2006; Zimmerman et al., 2006; ).

Preliminary indications for anomalous NP (Amieva et al., 2002; Amieva et al., 2004; Bondi et al., 2002; Ferraro, Wonderlich \& Johnson, 1997; Hogge, Salmon, \& Collette, 2008; Spieler, Balota \& Faust, 1996; Sullivan, Faust \& Balota, 1995; ).

Overall indication for reduced or abolished NP for negative stimuli (Frings, Wentura \& Holtz, 2007; Goeleven, De Raedt, Baert, \& Koster, 2006; Gotlib, Yue, \& Joorman, 2005; Joormann, 2004; Joorman, 2006; Leung, Lee, Yip, Li, \& Wong, 2009).

Either mixed results or no clear indication for anomalous NP (Filoteo, Rilling, \& Strayer, 2002; MacDonald, Antony, MacLeod, \& Swinson, 1999; Ozonoff, Strayer, McMahon, \& Filloux, 2003; Possin, Cagigas, Strayer, \& Filoteo, 2006; Wylie \& Stout, 2002; ).

Preliminary indications for anomalous NP (Braunstein-Bercovitz, 2003; Harrison \& Espelid, 2004; Kamijo \& Takeda, 2009; Skosnik, Chatterton, Swisher, \& Park, 2000; ).

Mixed results (Cameron, Hopper, \& Tiplady, 1996; Fillmore, Dixon, \& Schweizer, 2000).

No indication for an influence on NP (Della Casa, Höfer, ; Park, Knopick, McGurk, \& Meltzer, 2000; Rodway, Dienes, \& Schepman, 2000; Della Casa, Hofer, Weiner, \& Feldon, 1999).

No indication for impaired NP, regardless of the task (Amso \& Johnson, 2005; Frings, Feix, Röthig, Brüser, \& Junge, 2007; Pritchard \& Neumann, 2004; Pritchard \& Neumann, 2009; Simone \& McCormick, 1999; Wright, McMullin, Martis, Fischer, \& Rauch, 2005; )

No indication for impaired NP, regardless of the task (Buchner \& Mayr, 2004; Gamboz, Russo, \& Fox, 2002; Pesta \& Sanders, 2000; Titz, Behrendt, Menge, \& Hasselhorn, 2008; Verhaeghen \& De Meersman, 1998; ). symptomatology, acute psychosis, high severity of symptoms and lacking medication (though naturally not all of these factors need to be present at the same time). Taken together, while not all schizophrenic patients will show deficits in NP at all times, it is still safe to assume that specific impairments occurring in this disorder have a diminishing influence on NP.

Alzheimer's disease is defined by the gradual degeneration of cognitive abilities (Bartzokis, 2004). For standard identity NP tasks, NP effects were reported to be absent in patients with Alzheimer's disease (Amieva et al., 2002; Sullivan et al., 1995). On the other hand, enlarged or anomalous NP effects of patients with Alzheimer's disease were detected in NP-task using Stroop stimuli (Amieva et al., 2004; Bondi et al., 2002; Hogge, Salmon, \& Collette, 2008; Spieler et al., 1996).

Parkinson's disease has been linked both to higher levels of NP (Wylie \& Stout, 2002) and to lower levels (Filoteo et al., 2002). The possible reasons for this discrepancy were discussed in a joint comment (Stout et al., 2002). Since Parkinson's is caused by the degeneration of dopaminergic neurons, it is again of interest to note that chlorpromazine was associated with elevated NP effects in healthy participants (Beech et al., 1990). Both aforementioned studies applied spatial NP tasks; in an object-based paradigm, patients with
Parkinson's did not differ from controls (Possin et al., 2006). Parkinson's disease is defined by motoric symptoms and deficits, so that the applied task properties (spatial vs. nonspatial) might be especially critical.

There is no doubt that depressed participants process negative stimuli in a distorted manner. Is this bias reflected in NP tasks? A variant of the NP tasks in which targets and distractors are valenced is often used in samples of dysphoric or depressive participants. The stimuli are affectively toned in this paradigm and participants' have to classify the target's valence (positive or negative). The interference effect is found if the prime distractor valence is repeated as the probe target valence (Wentura, 1999). The NP effect (based on valence categorization) for negative stimuli has been found to be reduced or absent for dysphoric participants and participants with a history of depression (Frings et al., 2007; Goeleven et al., 2006; Joormann, 2004; Leung et al., 2009; but see Gotlib et al., 2005). High scores in rumination (repetitive, persistent thinking) are also linked to reduced NP effects for negative stimuli (Joormann, 2006). So far, comparatively little is known about the effect of acute episodes of depression on such affective NP effects.

The effect of ADHD has also been tested for NP paradigms. The results have been mixed so far, but seem to suggest 
no inherent deficits for ADHD patients (Marriott, 1998; Pritchard et al., 2007, 2008).

In sum, performance in NP tasks appears to be influenced by schizophrenia and schizotypy. Additionally, there is a strong indication for effects of depression, dysphoria and Alzheimer's disease as well.

\section{Differences in lifestyle (the effects of stress, sleep-depriva-} tion, drugs and physical activity). NP is influenced by various factors that we roughly categorize as the individual "lifestyle choices" of humans. Being a cognitive process, NP can be enlarged, reduced or altogether abolished if the physical wellbeing of a person is altered or compromised.

First, we will consider the effect of physical exercise. A physically active group of young adults exhibited larger NP effects in a spatial NP task than a group of adults with little regular physical activity (Kamijo \& Takeda, 2009). At the same time, a shorter latency of the stimulus-specific P3 ERP component was detected for the active participants when compared to the sedentary participants. In the active group, the P3 latency was significantly larger for the NP condition than for the control condition. No such difference could be observed within the less active group. These findings are interesting in the context of reports that link physical exercise to better cognitive functioning (Cotman \& Berchtold, 2002; Hillman, Erickson, \& Kramer, 2008; Lichtman \& Poser, 1983).

Regarding the effect of drugs, it is well established that alcohol reduces cognitive efficiency (Hindmarch, Kerr, \& Sherwood, 1991). In a group of male social drinkers, NP effects in a Stroop task were absent forty minutes after the consumption of alcohol. NP could again be observed sixty minutes after the intake (Fillmore et al., 2000). These test points corresponded with the ascending and declining portion of the blood alcohol curve (respectively). The blood alcohol concentration (BAC) averaged to $61.2 \mathrm{mg} / \mathrm{dl}$ before the first test and $59.7 \mathrm{mg} / \mathrm{dl}$ after the second test. Contrary to this finding, larger NP effects have been reported for participants that consumed low doses of alcohol compared to controls and participants that consumed high doses (Cameron et al., 1996). A low alcohol dose equaled $36.4 \mathrm{mg} / \mathrm{dl}$ in this study, while a high alcohol dose equaled $62.7 \mathrm{mg} / \mathrm{dl}$. Evidently, both findings are incompatible and further clarification is needed.

Similar to alcohol, sleep-deprivation generally is a cause of reduced cognitive functioning (Blagrove, Alexander, \& Horne, 2006; Jones \& Harrison, 2001). The effect of sleepdeprivation on NP was examined by Harrison and Espelid (2004). Participants with sufficient sleep were compared to participants awake for 34 continuous hours. The identity NP task consisted of three control and three IR conditions, one of each was non-degraded, and two of each consisted in either the target or the distractor being visually degraded. While the well-rested group showed comparably high NP effects for regular and degraded targets, the sleep-deprived participants were affected by the target degradation, and actually faster rather than slower on such IR trials. In contrast, the NP effect with standard targets was found to be unaffected for the sleepdeprived participants.

Stress is the unspecific physical reaction to a demand (Selye, 1983) and chronic stress is detrimental to health (Dhabhar \& Mcewen, 1997). Acute stress, however, can have a positive effect on selective attention (Chajut \& Algom, 2003) and it has been theorized that irrelevant task dimensions are more easily suppressed under stress, thereby strongly focusing attention on relevant (sometimes essential for survival) information (Easterbrook, 1959). Does acute stress then modulate NP? This question has been examined in a spatial NP task (Skosnik et al., 2000). The overall NP effect was reduced after a stress-treatment, which consisted of playing an aggressive video game. The level of NP was also inversely associated with a higher cortisol concentration 20 minutes after the treatment. However, no self-report measure of stress was taken, so it is unclear how stressful the video game actually was for the participants (all of which were young male adults). Braunstein-Bercovitz (2003) investigated the effect of varying levels of stress and cognitive load on NP. The main result was that NP was present in the high-stress and high-load condition, yet not in the high-stress and low-load condition. Stress therefore diminished NP, but this influence could be outweighed by cognitive load (for the influence of perceptual and cognitive load on NP, see Lavie \& Fox, 2000). So far, the relation between stress and NP is underspecified.

Mixed results have been reported for the effect of nicotine on NP. Rodway et al. (2000) tested the effect of smoking in an identity NP task. Their sample consisted of chronic smokers and was split into two groups, so that the participants either smoked prior to the test or just imitated smoking. All participants sustained from smoking one hour before testing. Significant NP effects were obtained for the smoking group, but not for the imitators. Contrary to this finding, smoking status was not related to NP in a spatial task (Park et al., 2000). Chronic smokers in this study sustained from smoking 24 hours before the test. They were then compared to nonsmokers at three different test points, one time before and two times after nicotine intake. The three test points were chosen to control for the effect of nicotine withdrawal, nicotine intake and the restoration of the baseline. Smoking also did not influence NP in a Stroop task (Della Casa et al., 1999) when chronic smokers in a deprived or non-deprived state were compared to nonsmokers. All in all, it is highly doubtful that nicotine influences NP in a significant way. This means that a heightened acetylcholine transmission, as induced by nicotine, has no major effect on the neural pathways that determine the NP process.

In sum, there is tentative evidence that physical activity seems to enlarge NP effects, while stress seems diminish them. It is doubtful whether nicotine influences NP effects at 
all, and the results for alcohol have been mixed and need clarification. The report on sleep-deprivation suggests that the NP effect is observable in sleep-deprived participants if an identity task is applied.

The effect of age. It was noted in 1989 that seven and eight year old children did not reliably display NP (Tipper, Bourque, Anderson, \& Brehaut, 1989). Since then, the relation between age and NP has been a special point of interest. May and colleagues (1995) concluded that this effect is diminished in young children and in old adults alike. More precisely, effects of identity NP appear to be reduced or non-existent in older adults and in young children (Connelly \& Hasher, 1993; Tipper, 1991; Tipper et al., 1989), while effects of spatial NP appear to be already present in young children (Tipper $\&$ McLaren, 1990). Fox (1995) proposed a "last in, first out" process for identity NP and a "first in, last out" process for spatial NP. It is plausible to assume that different types of NP develop at different stages in childhood and vary in their vulnerability to cognitive decline in old age. Has this pattern of findings been confirmed in the last eighteen years?

In the vast majority of studies, the earlier trends for age could not be replicated, both children and older adults displaying NP regardless of the applied task. For instance, Pesta and Sanders (2000) reported that 70-year-old adults exhibited NP effects as large and robust as younger adults. Titz et al. (2008) reported age-equivalent NP effects, yet at the same time age-related impairments in deletion control and access control. Verhaeghen and De Meersman (1998) conducted a meta-analysis on 20 studies specifically investigating the relation between age and performance in the Stroop task. The analysis showed that older adults demonstrate a reliable, but significantly smaller Stroop effect than younger adults. This finding has been contested by Gamboz, Russo, and Fox (2002), who provided a quantitative review for the relation between age and identity NP. Their analysis was not restricted to Stroop tasks alone, but did include every finding that Verhaeghen and De Meersman had examined as well. All in all, 36 single experiments were compiled and reassessed. No significant difference between younger and older adults was detected in regard to the magnitude of the NP effect. Age also proved to be irrelevant in an auditory NP task with musical stimuli where seventy year old participants displayed as much NP as younger adults (Buchner \& Mayr, 2004). Thus, identity NP does not seem to be diminished in older adults, which is in marked contrast to earlier reports (see Fox, 1995; May et al., 1995, for reviews).

Turning to the relation between young age and NP, spatial NP has been observed in boys ranging from 11-13 years (Wright, McMullin, Martis, Fischer, \& Rauch, 2005). Spatial and identity NP proved to be intact in groups of children, young adults and older adults alike (Simone \& McCormick, 1999). It has to be noted, however, that the identity NP task in this study also had a spatial component, so that intact identity NP cannot be inferred from this data. Less confounded identity tasks were used in other studies. Here, NP was intact in children ranging from 5-12 years (Pritchard \& Neumann, 2004, 2009). Children in a range of $6-11$ years also exhibited identity NP effects that were not significantly different from those of adult participants (Frings et al., 2007). One notable study was focused on NP effects in adults and 9 month old infants (Amso \& Johnson, 2005). Adults displayed NP in all conditions of a spatial task, while the infants - analyzed via an eye-tracker - showed NP if the inter-stimulus interval equaled $550 \mathrm{~ms}$ or $200 \mathrm{~ms}$, but not if the interval lasted only $67 \mathrm{~ms}$.

Taken together, there are no clear-cut effects of age on NP. Neither young children nor older adults reliably display impairment in various NP tasks, regardless of their specific nature. In the most extreme case, even infants exhibited NP, suggesting that the cognitive processes and neural structures contributing to NP are already present shortly after birth.

\section{What are the neural and electrophysiological correlates of NP?}

Imaging studies In the last decade, NP has been studied in relation to its neural correlates by means of functional magnetic resonance imaging (fMRI). So far, there are many procedural differences between the fMRI studies analyzing NP. These differences should naturally be associated with different clusters of brain activation (Krueger, Fischer, Heinecke, \& Hagendorf, 2007) and the reported correlations between varying brain regions and NP may reflect unique task demands (see Table 3 and Fig. 2 for a summary of findings). Nevertheless, there is tentative evidence for general neural correlates of NP across different tasks. An involvement of the right dorsolateral prefrontal cortex (DLPFC) has been correlated with deficits in NP in three imaging studies (Egner \& Hirsch, 2005; Krueger et al., 2007; Ungar et al., 2010), and an additional study reported correlates to adjoined prefrontal regions (Wright et al., 2005). We shortly discuss these studies.

To illustrate, Egner and Hirsch (2005) employed a Stroop task to examine the fMRI correlates of NP. The imaging data revealed two cluster differences between control and ignored repetition conditions, even though no NP effects were detected at the behavioral level. Both a cluster in the right dorsolateral prefrontal cortex (DLPFC) and a cluster in the right thalamic region showed increased activation in the IR condition. The DLPFC cluster was located mainly in the middle frontal gyrus but spread to the superior frontal sulcus (both classified as Brodmann area 8). The heightened activation in this cluster was positively correlated with the RTs in the ignored repetition trials. The negatively correlated thalamic cluster was centered at the right mediodorsal nucleus. The authors dissociated this 
effect from the conflict-related processing of the Stroop stimuli.

Ungar and colleagues (2010) employed a Stroop task in a sample of participants with schizophrenia and matched controls, also utilizing fMRI. While the effect of the Stroop conflict was observable in both groups, the NP effects were limited to the control group. During IR trials, the right DLPFC (BA 6) showed an increased activation for healthy control participants. De Zubicaray, McMahon, Eastburn, Pringle, and Lorenz (2006) examined the fMRI correlates of an identity NP task. A positive correlation was detected between the magnitude of the NP effect and increased activity in the left middle temporal gyrus.

The fMRI correlates of NP were also analyzed in a spatial task adapted from Tipper and colleagues (1994). In this study by Krueger and colleagues (2007), the stimuli either appeared abruptly (onset mode) or were masked at the beginning of the trials (no-onset mode). NP effects could only be observed in the onset mode. Here, a higher activation of the right inferior parietal lobule (BA 40) and the right DLPFC (BA 8/9) where observed in the IR compared to the control condition.

The neural correlates of spatial NP were also analyzed in boys ranging from 11-13 years (Wright et al., 2005; for the adapted task, see Swerdlow, Magulae, Filion, \& Zinner, 1996), though the sample size of just five participants makes it impossible to interpret the results. An activated prefrontal cluster was observed in the NP condition consisting of the right medial PFC (BA 10), left inferior (BA 47), and right inferior PFC (BA 44) as well as the left orbitofrontal cortex (BA 11). The left thalamus, left middle temporal cortex (BA 21) and left precentral gyrus (BA 6) also showed increased activation.

Thus, despite the procedural differences there is tentative evidence for an involvement of the right DLPFC in NP which is typically seen as relevant for action control. However, the detailed interpretation of the cognitive processes tapped by the activations of the PFC and the DLPFC diverge. In fact, Egner and Hirsch (2005) interpreted the heightened activation of the right DLPF as a result of the automatic retrieval of episodes, since the DLPFC has been associated with the evaluation of retrieved information (Rugg, Henson, \& Robb, 2003). Ungar and colleagues (2010) noted that activation of the bilateral DLPFC might reflect a disorder-related decline in the potency of distractor inhibition (May et al., 1995). Wright and colleagues (2005) attributed the observed activation of prefrontal clusters in terms of inhibitory processes. Specifically, the authors referred to a possible inhibitory network covering both the frontal and parietal cortex, encompassing not only the PFC (BA 8/9/10/44/45), but also the anterior cingulate cortex (BA 32/24), supplementary motor cortex (BA 6) and inferior parietal cortex (BA 40). Krueger and colleagues (2007) interpreted the activation of the right DLPFC in favor of the inhibition account (more precisely, the DLPFC 
Fig. 2 Regions of activation (difference scores) in IR conditions compared to control or other interference conditions. See text for further explanations. Note. Pictures built with BrainTutor HD (iOS version 3.0; 2013, brainvoyager.com).

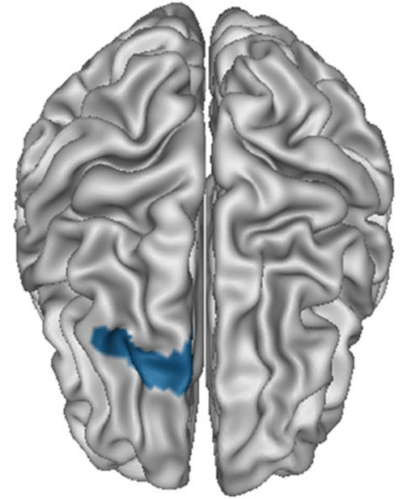

right DLPFC (BA 8) 3 studies

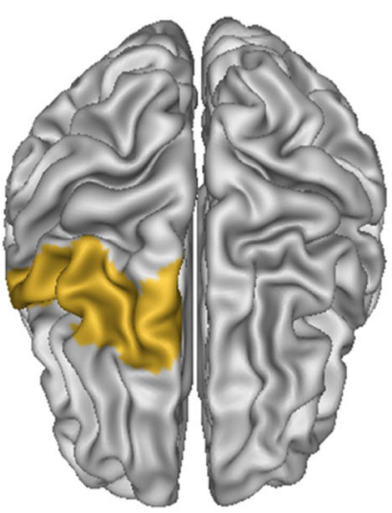

right DLPFC (BA 6) 3 studies

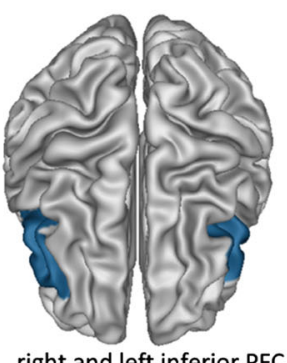

right and left inferior PFC (BA 44)

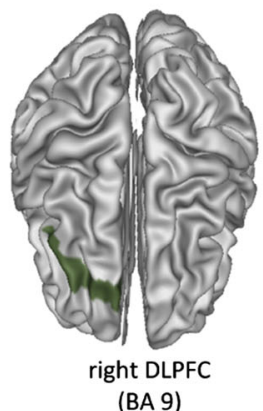

(BA 9)

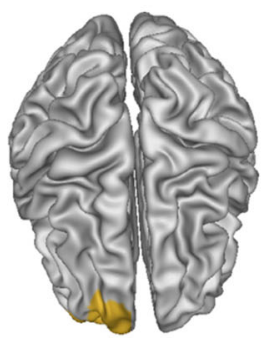

right medial PFC (BA 10)

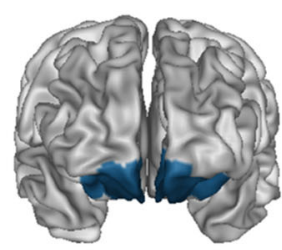

orbitofrontal cortex (BA 11)

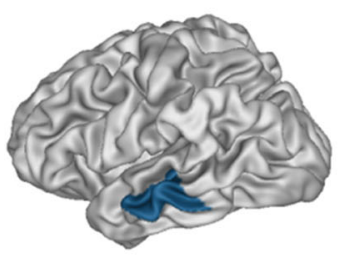

left middle temporal cortex (BA 21)

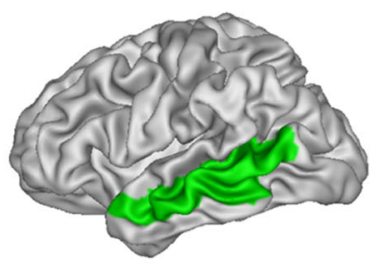

left middle temporal gyrus activation was seen as reflecting the top-down allocation of attentional resources).

Lesion studies The role of the frontal cortex for NP was highlighted by a study of Metzler and Parkin (2000), who analyzed eleven participants with bilateral and unilateral lesions in relation to age-matched controls. The lesions were relatively heterogeneous and located in various parts of the frontal lobe. All participants were tested in an identity NP task (Tipper \& Cranston, 1985). The comparison of the IR and control condition revealed significant differences between patients and controls. More specifically, six patients displayed positive priming, three displayed no effects of priming at all, and two displayed NP comparable to the controls. Stuss and colleagues (1999) studied spatial NP in patients and matched controls. Thirty-six patients with either frontal or posterior lesions were included in this study. NP was significantly altered in participants with unilateral right hemisphere lesions (both frontal and posterior); in fact, those groups of patients did not show NP effects at all. When the difficulty of the task was manipulated, a reduction in NP was observable in participants with left or bilateral frontal lesions. Taken together, in lesion studies, there are strong indications that the frontal lobe is directly involved in the processing of NP interference. This observation corresponds to the findings from imaging studies, as the majority of these also indicate a frontal involvement.

Electroencephalogram studies Electrophysiological components, including event-related potentials (ERPs), have also been correlated with NP effects. ERPs closely monitor the time-course of cognitive processes and can help to discriminate the onset at which different brain areas are activated and start to contribute to NP. However, it is somewhat problematic to derive specific ERP predictions from NP theories (see Mayr \& Buchner, 2007, for an overview of ERP correlates of NP). Thus, we just summarize findings from EEG studies without overly focusing on testing one theory against another.

Early sensory components have been assessed in various studies employing spatial NP tasks (Gibbons, 2006; Gibbons, 
Rammsayer, \& Stahl, 2006; Kathmann, Bogdahn, \& Endrass, 2006, Ruge \& Naumann, 2006). For instance, the parietal P1N1 (Gibbons et al., 2006) and the P3 amplitude (Kathmann et al., 2006) were found to be diminished in the IR relative to the control condition. In contrast, relative to control trials the posterior N2 amplitude was found to be enhanced in IR trials (Gibbons, 2006; Ruge \& Naumann, 2006). However, differences in early sensory components have not always been found in identity NP tasks (Gibbons, 2006; Gibbons et al., 2006). In lexical-decision tasks, a reduced N400 amplitude has been observed when comparing both the IR condition and the semantic IR condition to the control condition (Heil \& Rolke, 2004; Wagner, Baving, Berg, Cohen \& Rockstroh, 2006). A reduced late positive complex in the IR condition relative to the control condition has also been noted in several studies with auditory stimuli (Mayr, Niedeggen, Buchner, \& Pietrowsky, 2003; Mayr, Niedeggen, Buchner, \& Orgs, 2006) and visual stimuli (Wagner et al., 2006). Ceballos, Nixon, and Tivis (2003) found an increased P 3 amplitude for the IR trials in a same-different task with novel objects. Kathmann et al. found the equivalent result in a number identification task (2006). Mayr and Buchner (2007) concluded that the correlates of identity NP reflect rather late components of stimulus evaluation. However, in a couple of recent studies, an enhanced N200 component was observed in the IR trials of a NP Flanker task (Frings \& Groh-Bordin, 2007; Hinojosa, Pozo, Méndez-Bértolo, \& Luna, 2009). This significant effect only occurred when participants also displayed the behavioral correlates of NP and was therefore functionally linked to NP (Groh-Bordin \& Frings, 2009). Further, in a task of superimposed and colored pictures, the left-posterior P300 amplitude and frontal late positive complex (LPC) amplitude were reduced in IR trials and in AR trials alike (Behrendt et al., 2010); the same result was obtained in a Flanker NP task (Gibbons, 2009; Stahl \& Gibbons, 2007). The underlying processes were discussed as reflecting processes related to perceived prime-probe-similarity (Behrendt et al., 2010). Gibbons (2009) noticed a specific effect of NP on the N400 and Gibbons and Frings (2010) found an IR specific late P3 complex in a NP task with spatial uncertainty.

Taken together, the evidence concerning ERP correlate of NP is somewhat inconsistent. However, it should be noted that the procedural differences between the studies might partially account for the divergent findings. So far, it can be stated that early sensory aspects of NP are tapped by $\mathrm{P} 1$ and N1 components - mainly observed in location variants of the NP task whereas the N2 and P3 components as well as the LPC were observed in several identity tasks. In many reports, these early processing correlates $(\mathrm{P} 1 / \mathrm{N} 1)$ as well as the $\mathrm{N} 2$ are interpreted as evidence for inhibition (fitting to evidence from other paradigms in which, for example, the N2 is also discussed as response inhibition; e.g., Yeung \& Cohen, 2006). In contrast, later ERPs are discussed as evidence for retrieval (P3/ LPC).
What are the new specific findings on NP since $1995 ?$

A debate that has accompanied NP research from the beginning has been the assumption that NP is dependent on the presence of probe distractors. However, several recent publications question this dependence. In addition, NP has been observed in different modalities (vision, audition, touch, and smell) as well as in cross-modal settings. Finally, there is growing evidence that location NP and identity NP are differently modulated by several parameters, which may indicate different processes underlying spatial and object-based distractor processing.

The dependence of NP on the presence of probe distractors One well known, albeit puzzling, finding is that NP effects usually depend on the presence of distractor stimuli in the probe display (e.g., Allport et al., 1985; Lowe, 1979; Milliken et al., 1998; Milliken \& Tipper, 1998; Moore, 1994; Tipper \& Cranston, 1985; ). While some studies have found NP in the absence of probe distractors under specific conditions (Lowe, 1979; Moore, 1994; Neill, Terry, and Valdes, 1994; Neill \& Westberry, 1987) most early studies did not find NP if probe distractors were consistently absent. Memorybased accounts of NP explained these results on the basis that if the context changes between prime and probe display (e.g., two stimuli in the prime versus one stimulus in the probe) the likelihood of automatic memory retrieval is lowered. Hence, $\mathrm{NP}$ is less likely to occur. In contrast, the phenomenon posed severe problems for inhibition accounts. If it is assumed that the prime distractor is inhibited during the prime display presentation, then variations of the probe display should not diminish NP effects. Thus NP's dependence on the presence of probe distractors is usually interpreted as evidence against the inhibition model (Milliken, et al. 1998; Neill et al., 1992). A number of recent publications, however, have found NP with constantly absent probe distractors (Frings \& Spence, 2011; Frings \& Wentura, 2006a). The authors argued that in the typical NP task with $1 / 3$ attended repetition, $1 / 3$ ignored repetition, and $1 / 3$ control trials participants can strategically use the contingency between prime and probe stimuli (in $2 / 3$ of trials the probe target was displayed at the prime), particularly if the probe selection is easy (no distractors present). Thus, the fact that NP diminishes without probe distractors is due to participants' having enhanced cognitive resources so that they can exploit contingencies in a strategic way (see also Milliken, Thomson, Bleile, MacLellan, \& Giammarco, 2012).

In addition, it has been shown that the time participants need to respond to the probe displays can predict whether NP without probe distractors can be observed: the longer it takes to respond to the probe display (e.g., because the target is perceptually degraded) the likelier it is to observe NP (Frings \& Spence, 2011).

This pattern fits most easily with retrieval accounts of NP as these accounts presume that NP emerges if the retrieved 
prime episode interferes with probe responding; if one can respond to the probe before the retrieval process is finished, no interference emerges. In contrast, given enough time, the retrieval process will lead to interference even without probe distractors. Yet, generally speaking this pattern may also be incorporated into inhibition accounts but only by adding several further assumptions (see Frings \& Spence, 2011, for a discussion of this aspect). The important point is, however, that NP without probe distractors is not as rare as can be assumed if one looks at the older NP literature. It can be observed which in turn implies that the processes causing NP are not dependent on the presence of probe distractors. Two new variables (contingency and probe processing time) have been suggested which can possibly account for some of the inconsistencies.

NP in different modalities Originally NP was investigated with visual stimuli and most studies still use visual stimuli. However, NP has also been observed with auditory stimuli (Leboe, Mondor \& Leboe, 2006; Mayr \& Buchner, 2007), with tactile stimuli (Frings, Bader, \& Spence, 2008), and even with odors (Olsson, 1999). In addition, NP has been observed in cross-modal tasks (so far, only audition combined with vision; Buchner, Zabal, \& Mayr, 2003) and even more intriguing - in the study of Buchner et al. (2003) - the size of the NP effect did not depend on the modality. Thus, one may conclude that NP takes place at the level of amodal stimulus representations and hence NP is modality-independent. In this regard studies using bilinguals as participants and word stimuli from two different languages are noteworthy. In fact, Fox (1996) as well as others (e.g., Neumann, McCloskey, \& Felio, 1999) found NP even if the distractors in the prime were presented in another language as the targets in the probe; this was interpreted as evidence for NP at a conceptual level and fits with the idea of NP taking place at amodal stimulus representations. However, NP in touch compared to NP in vision seems to be much larger in terms of effect sizes - even if differences in processing difficulty are controlled (Frings, Amendt, \& Spence, 2011) - which is at odds with the idea of completely modality independent NP processes.

Stimulus repetition. In most experiments, a few selected stimuli are repeatedly used as targets and distractors. A single stimulus will serve as both many times throughout an experimental session. This directly affects NP. The NP effect increases in magnitude with the degree of stimulus repetition (Malley \& Strayer, 1995; Strayer \& Grison, 1999) and is even dependent on it, not occurring with yet unrepeated stimuli. In fact, a novel stimulus will lead to positive priming in the ignored repetition condition, causing a faster than usual reaction (Grison \& Strayer, 2001; Strayer \& Grison, 1999;). Strayer and Grison (1999) reported that NP occurred as a function of target repetition, while distractor repetition was irrelevant for the effect. Neill (1997) found repetition priming to be contingent on the context similarity (specifically the distractor-onset conditions) and this beneficial influence of similarity has been replicated (Tse, Hutchinson, \& Li, 2011; Wong, 2000). The effects of stimulus repetitions have been interpreted in terms of inhibition (Strayer, Drews, \& Albert, 2002) as well as episodic retrieval (Neill \& Joordens, 2002).

Location versus Identity NP It is clear that the ignoring of spatial distractors and object-distractors differs (cf. Neill, 2007). In particular, in spatial NP tasks, NP can be found even when targets and distractors are presented with a spatial separation of up to $12^{\circ}$ of visual angle (Chao \& Yeh, 2005; see also Guy \& Buckolz, 2007, for evidence showing that targetdistractor distance seems to play no role in spatial NP), whereas in identity NP tasks, NP usually starts to diminish when the target and distractor are separated by no more than $3^{\circ}$ of visual angle (e.g., Fox, 1994; Ruthruff \& Miller, 1995). In addition, in identity NP tasks, the selection of a target object in the prime displays often seems to be a precondition for NP to occur (though, see Joordens et al., 2006, for an exception; see also the work by Milliken and colleagues, 1998) whereas, in spatial NP tasks, no selection of a target location is needed for NP to occur (Guy, Buckolz, \& Pratt, 2004; Park \& Kanwisher, 1994). Finally, in tasks in which the identity and spatial features of stimuli were varied, location affected NP irrespective of whether the task was spatial or not whereas identity affected NP only when it was task-relevant (Frings \& Wentura, 2006b; Tipper et al., 1994). These results are in line with arguments from other attention paradigms that also support the claim that object location is processed in a different way than object identity (Constantinidis \& Steinmetz, 2005; Johnston \& Pashler, 1990; Lamy \& Tsal, 2000; Soto $\&$ Blanco, 2004). On top of that, there is an ongoing debate over whether the spatial NP effect in vision in fact reflects processes that lead to inhibition of return (IOR; e.g., Buckolz, Fitzgeorge, \& Knowles, 2012; Christie \& Klein, 2001; Milliken, Tipper, Houghton \& Lupianez, 2000) and thus should be separated from identity NP effects altogether.

It should be noted that for auditory location NP (Mayr, Hauke, \& Buchner, 2009; Mayr, Buchner, Möller, \& Hauke, 2011; Mayr, Möller, \& Buchner, 2014) a pattern of results has been observed that diverges from the ones observed in vision (Milliken et al., 1994) or touch (Frings, Mast, \& Spence, 2014). Spatial NP was found (i.e. worse performance if the prime distractor position was repeated as the probe target position); however, it completely depended on whether physical incongruence occurred at a repeated location. This finding is hard to explain in terms of inhibition or episodic retrieval theories but fits nicely with the feature mismatching theory suggested by Park and Kanwisher (1994). In a nutshell, this theory proposes that a location-identity discrepancy between the prime and probe display causes negative priming. 


\section{Conclusions for and future directions in Negative Priming}

A substantial body of work has been conducted on NP since the last major reviews were published in the mid-1990s. We have highlighted the key findings since then in Table 1. Theoretically, memory based accounts of NP have been further developed in the last decade. While some contemporary approaches, such as the temporal discrimination theory and the TIP/TAP approach, can be reconciled within a framework of inhibition and episodic retrieval theories, the stimulusresponse theory cannot. In addition, we have reviewed several areas of NP in which the results from the last two decades have disproved some assumptions made in the mid-1990s. In particular, it does not now seem that older age reduces NP effects, which was widely believed in earlier research (Fox, 1995; May et al., 1995). Likewise, the notion that the presence of a probe distractor is essential for negative priming to occur has now been overturned. Finally, it is clear that different processes are likely to contribute to spatial and identity NP effects. Taken together, we can conclude that NP tasks typically do not tap one single cognitive process. Instead, in most NP tasks several different cognitive processes are involved. This conclusion is not new to the literature (e.g., Neill, 2007; Tipper, 2001). However, the complexity of the NP phenomenon has not decreased despite several decades of intensive research. This has from our view at least two important implications.

The first implication relates to the growing research field in applied, developmental and clinical areas in which researchers are interested in inter-individual differences in inhibition or executive functioning. Against the background of the complex finding with respect to NP effects, it is important that researchers using NP as a measurement tool are careful with respect to the assumed cognitive mechanism they are investigating - inhibition or retrieval - given the findings that both processes are likely involved in most NP paradigms. In addition, the very low reliability of NP effects indicates that this paradigm is not suitable and should not be recommended for diagnostic purposes.

The second implication concerns research on the NP effect itself. Given the complex pattern of results one might ask what cognitive processes do NP tasks tap? Or, why should we use them? We would argue that this complexity might actually be taken as a strength. Selection of a relevant object from among competing momentarily irrelevant objects is a core cognitive ability. Without efficient selection, coherent interaction with a dynamic and complex environment becomes impossible. In this context, we would argue that the NP task can capture something of the multidimensional nature of selection. Unlike other interference or selection tasks (e.g., Stroop or flanker tasks) the NP task assesses what happens to the representation of previously encountered distractors - the aftereffects of ignoring.
Our review has revealed important milestones on the road to understanding the processes contributing to these aftereffects of ignoring and has highlighted important next steps. A primary conclusion we draw is that researchers now need to focus on teasing apart the underlying processes that drive NP effects. It is no longer acceptable to simply use NP tasks that reflect a mix of multiple processes without attempting to separate and understand these different processes and how they are affected by context. One future direction would be to investigate the circumstances under which stimulus-response binding contributes to NP effects (Mayr et al. 2009a, b). As we have argued above, it is difficult to reconcile stimulusresponse binding with many retrieval theories. By analyzing prime response retrieval errors one can estimate the degree of S-R binding in a particular NP task. In a recent review, Henson and colleagues (2014) recommended that S-R binding processes should be kept in mind when analyzing sequential priming effects. This clearly holds true for NP tasks as well.

Second, as Tram Neill (2007) has pointed out, the discourse concerning whether inhibition or retrieval produces NP now seems rather obsolete. Thus, one way for research to proceed is to investigate under which circumstances either or both processes predominantly lead to NP and why. In this regard, the level at which NP takes place is critical. It seems that NP at the level of perceptual features, spatial features or based on abstract representations can in different ways be linked to inhibition and retrieval. In several papers it was suggested that location NP might tap inhibition at the response level while $\mathrm{NP}$ at a central level might tap retrieval. It is interesting to note that the interpretation of ERP correlates of NP fit with this approach. In particular, N1/P1 components were found in location tasks (and interpreted as indexing inhibition) while the P3 and LPC components observed in identity tasks were typically interpreted as evidence for retrieval (but see the interpretation of the $\mathrm{N} 2$ component). Thus, the level at which NP effects emerge (based on the task used) should be analyzed under conditions which are likely to favor retrieval or inhibition (e.g., including a high amount of attended repetition trials is usually assumed to increase retrieval effects).

Third, the data summarized here suggest that spatial and identity NP should be considered as separate tasks, perhaps tapping into different underlying mechanisms. Thus, if the aim is to pinpoint cognitive processes contributing to NP effects, spatial and identity tasks should not be mixed. Indeed, many discussions about the processes underlying NP have mixed these tasks, which may have played a role in the confusion over what process is driving NP effects. This debate becomes even more complex, if one looks at the different influences of modality on spatial versus identity NP effects. For instance, while identity NP effects seem to be comparable across modalities this is not true for spatial NP effects.

Fourth, a further future line of research might involve the relationship between NP and neurotransmitters, particularly 
dopamine. Noudoost and Moore (2011) suggested that dopamine is a key neurotransmitter for selective, top-down regulated attention, while acetylcholine crucially modulates spatial, bottom-up directed attention (also see Bellgrove \& Mattingley, 2008). The latter result fits with the missing influence of nicotine on NP as nicotine leads to a heightened acetylcholine transmission. However, studies that analyze the influence of dopamine on selective attention in humans are scarce (see Schneider, Schote, Meyer, \& Frings, 2015, for an exception) but might prove quite useful to disentangle the different cognitive processes contributing to NP effects.

Finally, besides implications for paradigm-specific research on the NP effect, we suggest that it is important to integrate NP research into larger cognitive theories or architectures. Applying the TIP/TAP principle to NP, or understanding NP as a binding phenomenon (and thereby linking it to the theory of event coding), would seem to be fruitful ways to advance theory in this area. The same holds true for approaches to integrate NP into models of executive control (cf. Friedman \& Miyake, 2004). Models of NP might also prove to be useful in the development of models for selection in general. For example, the selective attention model of Houghton and Tipper $(1994,1996)$ can easily be applied to explain interference effects in a vast array of cognitive paradigms like the flanker or the Stroop paradigm (cf. Frings, Wentura, \& Wühr, 2012). This is where the complexity of the NP phenomenon might be seen as an advantage. When one is interested in understanding cognitive processes that contribute to distractor processing we need to account for the fact that several cognitive processes contribute and possibly interact while we try to ignore distracting information. While it is important to separate these processes and pinpoint them in a specific paradigm, it also is important that we do not forget the central goal, namely understanding cognition in general rather than a specific paradigm. The debates and complexity that the NP paradigm has elicited should prove informative for the development of general models of selection in human cognition.

Authors' Note We would like to thank Andrew Heathcote, Tram Neill, and an anonymous reviewer for their helpful feedback on a previous version of this article.

\section{References}

Allport, D. A., Tipper, S. P., \& Chmiel, N. (1985). Perceptual integration and post-categorical filtering. In M. I. Posner \& O. S. M. Marin (Eds.), Attention and performance. Hillsdale, NJ: Erlbaum.

Amieva, H., Lafont, S., Auriacombe, S., Le Carret, N., Dartigues, J.-F., Orgogozo, J.-M., \& Fabrigoule, C. (2002). Inhibitory breakdown and dementia of the Alzheimer type: A general phenomenon? Journal of Clinical and Experimental Neuropsychology, 24, 503516.
Amieva, H., Lafont, S., Rouch-Leroyer, I., Rainville, C., Dartigues, J.-F., Orgogozo, J.-M., \& Fabrigoule, C. (2004). Evidencing inhibitory deficits in Alzheimer's disease through interference effects and shifting disabilities in the Stroop test. Archives of Clinical Neuropsychology, 19, 791-803.

Amso, D., \& Johnson, S. P. (2005). Selection and inhibition in infancy: Evidence from the spatial negative priming paradigm. Cognition, 95, 27-36.

Bartzokis, G. (2004). Age-related myelin breakdown: A developmental model of cognitive decline and Alzheimer's disease. Neurobiology of Aging, 25, 5-18.

Bauer, E., Gebhardt, H., Ruprecht, C., Gallhofer, B., \& Sammer, G. (2012). Neuroimaging evidence for processes underlying repetition of ignored stimuli. PLOS ONE, 7, e36089.

Beech, A., Baylis, G. C., Smithson, P., \& Claridge, G. S. (1989a). Individual differences in schizotypy as reflected in cognitive measures of inhibition. British Journal of Clinical Psychology, 28, 117129.

Beech, A., \& Claridge, G. (1987). Individual differences in negative priming: Relations with schizotypal personality traits. British Journal of Psychology, 78, 349-356.

Beech, A., McManus, D., Baylis, G. C., Tipper, S. P., \& Agar, K. (1991). Individual differences in cognitive processes: Towards an explanation of schizophrenic symptomatology. British Journal of Psychology, 82, 417-426.

Beech, A., Powell, T., McWilliam, J., \& Claridge, G. (1989b). Evidence of reduced "cognitive inhibition" in schizophrenia. British Journal of Clinical Psychology, 28, 110-116.

Beech, A., Powell, T. J., McWilliam, J., \& Claridge, G. S. (1990). The effect of a small dose of chlorpromazine on a measure of "cognitive inhibition". Personality and Individual Differences, 11, 1141-1145.

Behrendt, J., Gibbons, H., Schrobsdorff, H., Ihrke, M., Herrmann, J. M., \& Hasselhorn, M. (2010). Event-related brain potential correlates of identity negative priming from overlapping pictures. Psychophysiology, 47, 921-930.

Bellgrove, M. A., \& Mattingley, J. B. (2008). Molecular genetics of attention. Annals of the New York Academy of Sciences, 1129, 200-212.

Blagrove, M., Alexander, C., \& Horne, J. A. (2006). The effects of chronic sleep reduction on the performance of cognitive tasks sensitive to sleep deprivation. Applied Cognitive Psychology, 9, 21-40.

Blaxton, T. A. (1989). Investigating dissociations among memory measures: Support for a transfer-appropriate processing framework. Journal of Experimental Psychology: Learning, Memory, and Cognition, 15, 657-668.

Bondi, M. W., Serody, A. B., Chan, A. S., Eberson-Shumate, S. C., Delis, D. C., Hansen, L. A., \& Salmon, D. P. (2002). Cognitive and neuropathologic correlates of Stroop Color-Word Test performance in Alzheimer's disease. Neuropsychology, 16, 335-343.

Braunstein-Bercovitz, H. (2003). Does stress enhance or impair selective attention? The effects of stress and perceptual load on negative priming. Anxiety, Stress, and Coping, 16, 345-357.

Buchner, A., \& Mayr, S. (2004). Auditory negative priming in younger and older adults. Quarterly Journal of Experimental Psychology Section A, 57, 769-787.

Buchner, A., Zabal, A., \& Mayr, S. (2003). Auditory, visual, and crossmodal negative priming. Psychonomic Bulletin \& Review, 10, $917-$ 923.

Buckolz, E., Fitzgeorge, L., \& Knowles, S. (2012). Spatial negative priming, but not inhibition of return, with central (foveal) displays. Psychology, 3, 666-674.

Buckolz, E., Goldfarb, A., \& Khan, M. (2004). The use of a distractorassigned response slows later responding in a location negative priming task. Attention, Perception, \& Psychophysics, 66, 837-845. 
Cameron, C.-A., Hopper, E. S., \& Tiplady, B. (1996). Ethanol and negative priming. Human Psychopharmacology: Clinical and Experimental, 11, 131-136.

Ceballos, N. A., Nixon, S. J., \& Tivis, R. (2003). Substance abuse-related P300 differences in response to an implicit memory task. Progress in Neuro-Psychopharmacology and Biological Psychiatry, 27, 157164.

Chajut, E., \& Algom, D. (2003). Selective attention improves under stress: Implications for theories of social cognition. Journal of Personality and Social Psychology, 85, 231-248.

Chao, H. F., \& Yeh, Y. Y. (2005). Location negative priming in identity discrimination relies on location repetition. Perception \& Psychophysics, 67, 789-801.

Chiappe, D. L., \& Macleod, C. M. (1995). Negative priming is not task bound: A consistent pattern across naming and categorization tasks. Psychonomic Bulletin \& Review, 2, 364-369.

Connelly, S. L., \& Hasher, L. (1993). Aging and the inhibition of spatial location. Journal of Experimental Psychology: Human Perception and Performance, 19, 1238-1250.

Constantinidis, C., \& Steinmetz, M. A. (2005). Posterior parietal cortex automatically encodes the location of salient stimuli. The Journal of Neuroscience, 25, 233-238.

Cotman, C. W., \& Berchtold, N. C. (2002). Exercise: A behavioral intervention to enhance brain health and plasticity. Trends in Neurosciences, 25, 295-301.

Christie, J., \& Klein, R. M. (2001). Negative priming for spatial location? Canadian Journal of Experimental Psychology/Revue canadienne de psychologie experimentale, 55, 24-38.

Dalrymple-Alford, E. C., \& Budayr, B. (1966). Examination of some aspects of the Stroop color-word test. Perceptual and Motor Skills, 23, 1211-1214

De Zubicaray, G., McMahon, K., Eastburn, M., Pringle, A., \& Lorenz, L. (2006). Classic identity negative priming involves accessing semantic representations in the left anterior temporal cortex. Neurolmage, 33, 383-390.

Della Casa, V., Höfer, I., Weiner, I., \& Feldon, J. (1999). Effects of smoking status and schizotypy on latent inhibition. Journal of Psychopharmacology, 13, 45-57.

Dhabhar, F. S., \& Mcewen, B. S. (1997). Acute stress enhances while chronic stress suppresses cell-mediated immunity in vivo: A potential role for leukocyte trafficking. Brain, Behavior, and Immunity, 11, 286-306.

Easterbrook, J. A. (1959). The effect of emotion on cue utilization and the organization of behavior. Psychological Review, 66, 183-201.

Egner, T., \& Hirsch, J. (2005). Where memory meets attention: Neural substrates of negative priming. Journal of Cognitive Neuroscience, 17, $1774-1784$

Elvevag, B., \& Goldberg, T. E. (2000). Cognitive impairment in schizophrenia is the core of the disorder. Critical Reviews in Neurobiology, 14, 1-21.

Ferraro, F. R., Wonderlich, S., \& Johnson, K. (1997). Do individuals at risk for eating disorders exhibit negative priming deficits? The Journal of General Psychology, 124, 381-390.

Fillmore, M. T., Dixon, M. J., \& Schweizer, T. A. (2000). Alcohol affects processing of ignored stimuli in a negative priming paradigm. Journal of Studies on Alcohol and Drugs, 61, 571-578.

Filoteo, J. V., Rilling, L. M., \& Strayer, D. L. (2002). Negative priming in patients with Parkinson's disease: Evidence for a role of the striatum in inhibitory attentional processes. Neuropsychology, 16, 230-241.

Fox, E. (1994). Interference and negative priming from ignored distractors: The role of selection difficulty. Perception \& Psychophysics, 56, 565-574.

Fox, E. (1995). Negative priming from ignored distractors in visual selection: A review. Psychonomic Bulletin \& Review, 2, 145-173.
Fox, E. (1996). Cross-language priming from ignored words: Evidence for a common representational system in bilinguals. Journal of Memory and Language, 35, 353-370.

Fox, E., \& De Fockert, J. W. (1998). Negative priming depends on primeprobe similarity: Evidence for episodic retrieval. Psychonomic Bulletin \& Review, 5, 107-113.

Friedman, N. P., \& Miyake, A. (2004). The relations among inhibition and interference control functions: A latent-variable analysis. Journal of Experimental Psychology: General, 133, 101-135.

Frings, C. (2008). Analyzing the relationship between target-to-target and distractor-to-targetrepetitions: Evidence for a common mechanism. Quarterly Journal of Experimental Psychology, 61, 1641-1649.

Frings, C., Amendt, A., \& Spence, C. (2011). When seeing doesn't matter: Assessing the after-effects of tactile distractor processing in the blind and the sighted. Journal of Experimental Psychology: Human Perception and Performance, 37, 1174-1181.

Frings, C., Bader, R., \& Spence, C. (2008). Selection in touch: Negative priming with tactile stimuli. Attention, Perception, \& Psychophysics, 70, 516-523.

Frings, C., \& Eder, A. B. (2009). The time-course of masked negative priming. Experimental Psychology, 56, 301-306.

Frings, C., Feix, S., Röthig, U., Brüser, C., \& Junge, M. (2007a). Children do show negative priming: Further evidence for early development of an intact selective control mechanism. Developmental Psychology, 43, 1269-1273.

Frings, C., \& Groh-Bordin, C. (2007). Electrophysiological correlates of visual identity negative priming. Brain Research, 1176, 82-91.

Frings, C., Mast, F., \& Spence, C. (2014). Tactile spatial negative priming occurs without feature-mismatch. Attention, Perception, \& Psychophysics, 76, 1-10. doi:10.3758/s13414-014-0721-4

Frings, C., Rothermund, K., \& Wentura, D. (2007b). Distractor repetitions retrieve previous responses to targets. The Quarterly Journal of Experimental Psychology, 60, 1367-1377.

Frings, C., \& Spence, C. (2011). Increased perceptual and conceptual processing difficulty makes the immeasurable measurable: Negative priming in the absence of probe distractors. Journal of Experimental Psychology: Human Perception and Performance, 37, 72-84.

Frings, C., \& Wentura, D. (2005). Negative priming with masked distractor-only prime trials: Awareness moderates negative priming. Experimental Psychology, 52, 131-139.

Frings, C., \& Wentura, D. (2006a). Strategy effects counteract distractor inhibition: Negative priming with constantly absent probe distractors. Journal of Experimental Psychology: Human Perception and Performance, 32, 854-864.

Frings, C., \& Wentura, D. (2006b). Negative priming is stronger for task relevant dimensions: Evidence of flexibility in selective ignoring of distractor information. Quarterly Journal of Experimental Psychology, 59, 683-693.

Frings, C., Wentura, D., \& Holtz, M. (2007c). Dysphorics cannot ignore unpleasant information. Cognition and Emotion, 21, 1525-1534.

Frings, C., Wentura, D., \& Wühr, P. (2012). On the fate of distractor representations. Journal of Experimental Psychology: Human Perception \& Performance, 38, 570-575.

Frings, C., \& Wühr, P. (2007). On distractor-repetition benefits in the negative-priming paradigm. Visual Cognition, 15, 166-178.

Fuller, R., Frith, C. D., \& Jahanshahi, M. (2000). Reduced negative priming does indicate reduced cognitive inhibition in schizophrenia. Cognitive Neuropsychiatry, 5, 21-35.

Gamboz, N., Russo, R., \& Fox, E. (2002). Age differences and the identity negative priming effect: An updated meta-analysis. Psychology and Aging, 17, 525-531.

Gibbons, H. (2006). An event-related potential investigation of varieties of negative priming. Journal of Psychophysiology, 20, 170-185. 
Gibbons, H. (2009). Functional brain-electrical correlates of negative priming in the flanker task: Evidence for episodic retrieval. Psychophysiology, 46, 807-817.

Gibbons, H., \& Frings, C. (2010). Flanker negative priming from spatially unpredictable primes: An ERP study. International Journal of Psychophysiology, 75, 339-348.

Gibbons, H., Rammsayer, T. H., \& Stahl, J. (2006). Multiple sources of positive-and negative-priming effects: An event-related potential study. Memory \& cognition, 34, 172-186.

Gibbons, H., \& Stahl, J. (2008). Early activity in the lateralized readiness potential suggests prime-response retrieval as a source of negative priming. Experimental Psychology, 55, 164-172.

Goeleven, E., De Raedt, R., Baert, S., \& Koster, E. H. (2006). Deficient inhibition of emotional information in depression. Journal of Affective Disorders, 31, 208-218.

Gotlib, I. H., Yue, D. N., \& Joormann, J. (2005). Selective attention in dysphoric individuals: The role of affective interference and inhibition. Cognitive Therapy and Research, 29, 417-432.

Grison, S., \& Strayer, D. L. (2001). Negative priming and perceptual fluency: More than what meets the eye. Attention, Perception, \& Psychophysics, 63, 1063-1071.

Groh-Bordin, C., \& Frings, C. (2009). Where has all the inhibition gone? Insights from electrophysiological measures into negative priming without probe distractors. Brain and Cognition, 71, 92-98.

Guy, S., \& Buckolz, E. (2007). The locus and modulation of the location negative priming effect. Psychological Research, 71, 178-191.

Guy, S., Buckolz, E., \& Pratt, J. (2004). The influence of distractor-only prime trials on the location negative priming mechanism. Experimental Psychology, 51, 4-14.

Harrison, Y., \& Espelid, E. (2004). Loss of negative priming following sleep deprivation. Quarterly Journal of Experimental Psychology Section A, 57, 437-446.

Hasher, L., Stoltzfus, E. R., Zacks, R. T., \& Rypma, B. (1991). Age and inhibition. Journal of Experimental Psychology: Learning, Memory, and Cognition, 17, 163-169.

Healy, D., \& Burt, J. S. (2003). Attending to the distractor and old/new discriminations in negative priming. The Quarterly Journal of Experimental Psychology Section A, 56, 421-443.

Heil, M., \& Rolke, B. (2004). Unattended distractor-induced priming in a visual selective attention task: N400 effects in the absence of RT effects. Journal of Psychophysiology, 18, 164-169.

Hervey, A. S., Epstein, J. N., \& Curry, J. F. (2004). Neuropsychology of adults with attention-deficit/hyperactivity disorder: A meta-analytic review. Neuropsychology, 18, 485-503.

Hillman, C. H., Erickson, K. I., \& Kramer, A. F. (2008). Be smart, exercise your heart: Exercise effects on brain and cognition. Nature Reviews Neuroscience, 9, 58-65.

Hinojosa, J. A., Pozo, M. A., Méndez-Bértolo, C., \& Luna, D. (2009). Event-related potential correlates of visual identity negative priming unbiased by trial-by-trial effects. Brain and Cognition, 69, 531-537.

Hoenig, K., Hochrein, A., Müller, D. J., \& Wagner, M. (2002). Different negative priming impairments in schizophrenia and subgroups of obsessive-compulsive disorder. Psychological Medicine, 32, 459468.

Hogge, M., Salmon, E., \& Collette, F. (2008). Interference and negative priming in normal aging and in mild Alzheimer's disease. Psychologica Belgica, 48, 1-23.

Hommel, B. (1998). Event files: Evidence for automatic integration of stimulus-response episodes. Visual Cognition, 5, 183-216.

Hommel, B. (2004). Event files: Feature binding in and across perception and action. Trends in Cognitive Sciences, 8, 494-500.

Hommel, B., Müsseler, J., Aschersleben, G., \& Prinz, W. (2001). The theory of event coding (TEC): A framework for perception and action planning. Behavioral and Brain Sciences, 24, 849-878.

Houghton, G., \& Tipper, S. P. (1994). A model of inhibitory mechanisms in selective attention. In D. Dragenbach \& T. H. Carr (Eds.),
Inhibitory processes in attention, memory, and language (pp. 53112). San Diego, CA: Academic Press.

Johnston, J. C., \& Pashler, H. (1990). Close binding of identity and location in visual feature perception. Journal of Experimental Psychology: Human Perception and Performance, 16, 843-856.

Jones, K., \& Harrison, Y. (2001). Frontal lobe function, sleep loss and fragmented sleep. Sleep Medicine Reviews, 5, 463-475.

Joordens, S., Betancourt, I., \& Spalek, T. M. (2006). Selective attention versus selection for action: Negative priming is not the result of distractors being unattended. Perception \& Psychophysics, 68, 890-896.

Joormann, J. (2004). Attentional bias in dysphoria: The role of inhibitory processes. Cognition and Emotion, 18, 125-147.

Joormann, J. (2006). Differential effects of rumination and dysphoria on the inhibition of irrelevant emotional material: Evidence from a negative priming task. Cognitive Therapy and Research, 30, 149 160.

Kahan, T. A. (2000). Negative priming from masked words: Retrospective prime clarification or center-surround inhibition? Journal of Experimental Psychology: Learning, Memory, and Cognition, 26, 1392-1410.

Kamijo, K., \& Takeda, Y. (2009). General physical activity levels influence positive and negative priming effects in young adults. Clinical Neurophysiology, 120, 511-519.

Kane, M. J., May, C. P., Hasher, L., Rahhal, T., \& Stoltzfus, E. R. (1997). Dual mechanisms of negative priming. Journal of Experimental Psychology: Human Perception and Performance, 23, 632-650.

Kathmann, N., Bogdahn, B., \& Endrass, T. (2006). Event-related brain potential variations during location and identity negative priming. Neuroscience Letters, 394, 53-56.

Kolers, P. A. (1976). Reading a year later. Journal of Experimental Psychology: Human Learning and Memory, 2, 554-565.

Krueger, F., Fischer, R., Heinecke, A., \& Hagendorf, H. (2007). An fMRI investigation into the neural mechanisms of spatial attentional selection in a location-based negative priming task. Brain Research, $1174,110-119$.

Lamy, D., \& Tsal, Y. (2000). Object features, object locations, and object files: Which does selective attention activate and when? Journal of Experimental Psychology: Human Perception and Performance, 26, 1387-1400.

Laplante, L., Everett, J., \& Thomas, J. (1992). Inhibition through negative priming with Stroop stimuli in schizophrenia. British Journal of Clinical Psychology, 31, 307-326.

Lavie, N., \& Fox, E. (2000). The role of perceptual load in negative priming. Journal of Experimental Psychology: Human Perception and Performance, 26, 1038-1052.

Leboe, J. P., Mondor, T. A., \& Leboe, L. C. (2006). Feature mismatch effects in auditory negative. Attention, Perception, \& Psychophysics, 68, 897-910.

Leboe, J. P., Whittlesea, B. W. A., \& Milliken, B. (2005). Selective and nonselective transfer: Positive and negative priming in a multipletask environment. Journal of Experimental Psychology: Learning, Memory, and Cognition, 31, 1001-1029.

Leung, K.-K., Lee, T. M., Yip, P., Li, L. S., \& Wong, M. M. (2009). Selective attention biases of people with depression: Positive and negative priming of depression-related information. Psychiatry Research, 165, 241-251.

Lichtman, S., \& Poser, E. G. (1983). The effects of exercise on mood and cognitive functioning. Journal of Psychosomatic Research, 27, 43 52.

Lowe, D. G. (1979). Strategies, context, and the mechanism of response inhibition. Memory \& Cognition, 7, 382-389.

Lucas, M. (2000). Semantic priming without association: A meta-analytic review. Psychonomic Bulletin \& Review, 7, 618-630. 
MacDonald, P. A., Antony, M. M., MacLeod, C. M., \& Swinson, R. P. (1999a). Negative priming for obsessive-compulsive checkers and noncheckers. Journal of Abnormal Psychology, 108, 679-686.

MacDonald, P. A., Joordens, S., \& Seergobin, K. N. (1999b). Negative priming effects that are bigger than a breadbox: Attention to distractors does not eliminate negative priming, it enhances it. Memory \& Cognition, 27, 197-207.

MacLeod, C. M. (2007). The concept of inhibition in cognition. In D. S. Gorfein \& C. N. MacLeod (Eds.), Inhibition in cognition (pp. 3-24). Washington, DC: American Psychological Association.

MacLeod, C. M., Chiappe, D. L., \& Fox, E. (2002). The crucial roles of stimulus matching and stimulus identity in negative priming. Psychonomic Bulletin \& Review, 9, 521-528.

MacQueen, G. M., Galway, T., Goldberg, J. O., \& Tipper, S. P. (2003). Impaired distractor inhibition in patients with schizophrenia on a negative priming task. Psychological Medicine, 33, 121-129.

Malley, G. B., \& Strayer, D. L. (1995). Effect of stimulus repetition on positive and negative identity priming. Attention, Perception, \& Psychophysics, 57, 657-667.

Marriott, M. J. (1998). Selective attention, negative priming, and hyperactivity: Investigating the ' $\mathrm{AD}$ ' in ADHD. Retrieved from http:// digitalcommons.mcmaster.ca/opendissertations/2141/

May, C. P., Kane, M. J., \& Hasher, L. (1995). Determinants of negative priming. Psychological Bulletin, 118, 35-54.

Mayr, S., \& Buchner, A. (2006). Evidence for episodic retrieval of inadequate prime responses in auditory negative priming. Journal of Experimental Psychology: Human Perception and Performance, 32, 932-943.

Mayr, S., \& Buchner, A. (2007). Negative priming as a memory phenomenon: A review of 20 years of negative priming research. Zeitschrift für Psychologie/Journal of Psychology, 215, 35-51.

Mayr, S., Buchner, A., \& Dentale, S. (2009a). Prime retrieval of motor responses in negative priming. Journal of Experimental Psychology: Human Perception and Performance, 35, 408-423.

Mayr, S., Buchner, A., Möller, M., \& Hauke, R. (2011). Spatial and identity negative priming in audition: Evidence of feature binding in auditory spatial memory. Attention, Perception, \& Psychophysics, $73,1710-1732$

Mayr, S., Hauke, R., \& Buchner, A. (2009b). Auditory location negative priming: A case of feature mismatch. Psychonomic Bulletin \& Review, 16, 845-849.

Mayr, U. (2007). Inhibition of task sets. In D. S. Gorfein \& C. M. MacLeod (Eds.), Inhibition in cognition (pp. 27-44). Washington, DC: American Psychological Association.

Mayr, U., \& Keele, S. W. (2000). Changing internal constraints on action: The role of backward inhibition. Journal of Experimental Psychology: General, 129, 4-26.

Mayr, S., Möller, M., \& Buchner, A. (2014). Auditory spatial negative priming: What is remembered of irrelevant sounds and their locations? Psychological research, 78(3), 423-438.

Mayr, S., Niedeggen, M., Buchner, A., \& Orgs, G. (2006). The level of reaction time determines the ERP correlates of auditory negative priming. Journal of Psychophysiology, 20, 186-194.

Mayr, S., Niedeggen, M., Buchner, A., \& Pietrowsky, R. (2003). ERP correlates of auditory negative priming. Cognition, 90, 11-21.

McNamara, T. P., \& Holbrook, J. B. (2003). Semantic memory and priming: Handbook of psychology. Retrieved from http://onlinelibrary. wiley.com/doi/10.1002/0471264385.wei0416/full

Metzler, C., \& Parkin, A. J. (2000). Reversed negative priming following frontal lobe lesions. Neuropsychologia, 38, 363-379.

Milliken, B., \& Joordens, S. (1996). Negative priming without overt prime selection. Canadian Journal of Experimental Psychology/ Revue canadienne de psychologie expérimentale, 50, 333-346.

Milliken, B., Joordens, S., Merikle, P. M., \& Seiffert, A. E. (1998). Selective attention: A reevaluation of the implications of negative priming. Psychological Review, 105, 203-229.
Milliken, B., Thomson, D. R., Bleile, K., MacLellan, E., \& Giammarco, M. (2012). Context-specific control and the Stroop negative priming effect. The Quarterly Journal of Experimental Psychology, 65, $1430-1448$.

Milliken, B., \& Tipper, S. P. (1998). Attention and inhibition. In H. Pashler (Ed.), Attention (pp. 191-222). New York, NY: Psychology Press.

Milliken, B., Tipper, S. P., Houghton, G., \& Lupiáñez, J. (2000). Attending, ignoring, and repetition: On the relation between negative priming and inhibition of return. Perception \& Psychophysics, 62, 1280-1296.

Milliken, B., Tipper, S. P., \& Weaver, B. (1994). Negative priming in a spatial localization task: Feature mismatching and distractor inhibition. Journal of Experimental Psychology: Human Perception and Performance, 20, 624-646.

Minas, R. K., \& Park, S. (2007). Attentional window in schizophrenia and schizotypal personality: Insight from negative priming studies. Applied and Preventive Psychology, 12, 140-148.

Moore, C. M. (1994). Negative priming depends on probe-trial conflict: Where has all the inhibition gone? Attention, Perception, \& Psychophysics, 56, 133-147.

Morris, C. D., Bransford, J. D., \& Franks, J. J. (1977). Levels of processing versus transfer appropriate processing. Journal of Verbal Learning and Verbal Behavior, 16, 519-533.

Moritz, S., \& Andresen, B. (2004). Reduced negative priming in schizotypy: Failure to replicate. British Journal of Clinical Psychology, 43, 211-215.

Moritz, S. H., Mass, R., \& Junk, U. (1998). Further evidence of reduced negative priming in positive schizotypy. Personality and Individual Differences, 24, 521-530.

Moritz, S., Ruff, C., Wilke, U., Andresen, B., Krausz, M., \& Naber, D. (2001). Negative priming in schizophrenia: Effects of masking and prime presentation time. Schizophrenia Research, 48, 291-299.

Neely, J. H. (1991). Semantic priming effects in visual word recognition: A selective review of current findings and theories. In D. Besner \& G. W. Humphreys (Eds.), Basic processes in reading: Visual word recognition (pp. 265-353). London, England: Routledge.

Neill, W. T. (1977). Inhibition and facilitation processes in selective attention. Journal of Experimental Psychology: Human Perception and Performance, 3, 444-450.

Neill, W. T. (1997). Episodic retrieval in negative priming and repetition priming. Journal of Experimental Psychology: Learning, Memory, and Cognition, 23, 1291-1305.

Neill, W. T. (2007). Mechanisms of transfer-inappropriate processing. In D. S. Gorfein \& C. M. MacLeod (Eds.), Inhibition in cognition (pp. 63-78). Washington, DC: American Psychological Association.

Neill, W. T., \& Joordens, S. (2002). Negative priming and multiple repetition: A reply to Grison and Strayer (2001). Attention, Perception, \& Psychophysics, 64, 855-860.

Neill, W. T., \& Kahan, T. A. (1999). Response conflict reverses priming: A replication. Psychonomic Bulletin \& Review, 6, 304-308.

Neill, W. T., \& Mathis, K. M. (1998). Transfer-inappropriate processing negative priming and related phenomena. Psychology of Learning and Motivation, 38, 1-44.

Neill, W. T., Terry, K. M., \& Valdes, L. A. (1994). Negative priming without probe selection. Psychonomic Bulletin \& Review, 1(1), $119-121$

Neill, W. T., \& Valdes, L. A. (1992). Persistence of negative priming: Steady state or decay? Journal of Experimental Psychology: Learning, Memory, and Cognition, 18, 565-576.

Neill, W. T., \& Valdes, L. A. (1996). Facilitatory and inhibitory aspects of attention. In A. F. Kramer, M. G. H. Coles, \& G. D. Logan (Eds.), Converging operations in the study of visual selective attention (pp. 77-106). Washington, DC: American Psychological Association. 
Neill, W. T., \& Westberry, R. L. (1987). Selective attention and the suppression of cognitive noise. Journal of Experimental Psychology: Learning, Memory, and Cognition, 13, 327-334.

Neumann, E., McCloskey, M. S., \& Felio, A. C. (1999). Cross-language positive priming disappears, negative priming does not: Evidence for two sources of selective inhibition. Memory \& Cognition, 27, $1051-1063$

Noudoost, B., \& Moore, T. (2011). The role of neuromodulators in selective attention. Trends in Cognitive Sciences, 15, 585-591.

Olsson, M. J. (1999). Implicit testing of odor memory: Instances of positive and negative repetition priming. Chemical Senses, 24, $347-$ 350

Oltmanns, T. F., Weintraub, S., Stone, A. A., \& Neale, J. M. (1978). Cognitive slippage in children vulnerable to schizophrenia. Journal of Abnormal Child Psychology, 6, 237-245.

Ozonoff, S., Strayer, D. L., McMahon, W. M., \& Filloux, F. (2003). Inhibitory deficits in Tourette syndrome: A function of comorbidity and symptom severity. Journal of Child Psychology and Psychiatry, 39, 1109-1118

Park, J., \& Kanwisher, N. (1994). Negative priming for spatial locations: Identity mismatching, not distractor inhibition. Journal of Experimental Psychology: Human Perception and Performance, 20, 613-623.

Park, S., Knopick, C., McGurk, S., \& Meltzer, H. Y. (2000). Nicotine impairs spatial working memory while leaving spatial attention intact. Neuropsychopharmacology, 22, 200-209.

Park, S., Lenzenweger, M. F., Püschel, J., \& Holzman, P. S. (1996). Attentional inhibition in schizophrenia and schizotypy: A spatial negative priming study. Cognitive Neuropsychiatry, 1, 125-150.

Pesta, B. J., \& Sanders, R. E. (2000). Aging and negative priming: Is ignored information inhibited or remembered? Experimental Aging Research, 26, 37-56.

Possin, K. L., Cagigas, X. E., Strayer, D. L., \& Filoteo, J. V. (2006). Lack of impairment in patients with Parkinson's disease on an objectbased negative priming task. Perceptual and Motor Skills, 102, 219-230.

Pritchard, V. E., \& Neumann, E. (2004). Negative priming effects in children engaged in nonspatial tasks: Evidence for early development of an intact inhibitory mechanism. Developmental Psychology, 40, 191-203.

Pritchard, V. E., \& Neumann, E. (2009). Avoiding the potential pitfalls of using negative priming tasks in developmental studies: Assessing inhibitory control in children, adolescents, and adults. Developmental Psychology, 45, 272-283.

Pritchard, V. E., Neumann, E., \& Rucklidge, J. J. (2007). Interference and negative priming effects in adolescents with attention deficit hyperactivity disorder. The American Journal of Psychology, 120, 91122

Pritchard, V. E., Neumann, E., \& Rucklidge, J. J. (2008). Selective attention and inhibitory deficits in ADHD: Does subtype or comorbidity modulate negative priming effects? Brain and Cognition, 67, 324339.

Rodway, P., Dienes, Z., \& Schepman, A. (2000). The effects of cigarette smoking on negative priming. Experimental and Clinical Psychopharmacology, 8, 104-111.

Roediger, H. L. (1990). Implicit memory: Retention without remembering. American Psychologist, 45, 1043-1056.

Rothermund, K., Wentura, D., \& De Houwer, J. (2005). Retrieval of incidental stimulus-response associations as a source of negative priming. Journal of Experimental Psychology: Learning, Memory, and Cognition, 31, 482-495.

Ruge, H., \& Naumann, E. (2006). Brain-electrical correlates of negative location priming under sustained and transient attentional context conditions. Journal of Psychophysiology, 20, 160-169.
Rugg, M. D., Henson, R. N., \& Robb, W. G. (2003). Neural correlates of retrieval processing in the prefrontal cortex during recognition and exclusion tasks. Neuropsychologia, 41, 40-52.

Ruthruff, E., \& Miller, J. (1995). Negative priming depends on ease of selection. Attention, Perception, \& Psychophysics, 57, 715-723.

Salo, R., Henik, A., Nordahl, T. E., \& Robertson, L. C. (2002). Immediate versus sustained processing in schizophrenia. Journal of the International Neuropsychological Society, 8, 794-803.

Schneider, K. K., Schote, A. B., Meyer, J., \& Frings, C. (2015). Genes of the dopaminergic system selectively modulate top-down but not bottom-up attention. Cognitive, Affective, \& Behavioral Neuroscience, 15, 104-116.

Selye, H. (1983). Stress research. In C. L. Cooper (Ed.), Issues for the eighties. New York, NY: John Wiley \& Sons.

Shiu, L.-P., \& Kornblum, S. (1996). Negative priming and stimulus-response compatibility. Psychonomic Bulletin and Review, 3, 510514.

Simone, P. M., \& McCormick, E. B. (1999). Effect of a defining feature on negative priming across the life span. Visual Cognition, 6, 587606.

Skosnik, P. D., Chatterton, R. T., Swisher, T., \& Park, S. (2000). Modulation of attentional inhibition by norepinephrine and cortisol after psychological stress. International Journal of Psychophysiology, 36, 59-68.

Soto, D., \& Blanco, M. J. (2004). Spatial attention and object-based attention: A comparison within a single task. Vision Research, 44, 69-81.

Spieler, D. H., Balota, D. A., \& Faust, M. E. (1996). Stroop performance in healthy younger and older adults and in individuals with dementia of the Alzheimer's type. Journal of Experimental Psychology: Human Perception and Performance, 22, 461-479.

Stahl, J., \& Gibbons, H. (2007). Event-related brain potentials support episodic-retrieval explanations of flanker negative priming. Experimental Brain Research, 181, 596-606.

Steel, C., Haworth, E. J., Peters, E., Hemsley, D. R., Sharma, T., Gray, J. A., ... \& Williams, S. C. R. (2001). Neuroimaging correlates of negative priming. Neuroreport, 12, 3619-3625.

Stout, J. C., Wylie, S. A., \& Filoteo, J. V. (2002). Divergent findings regarding negative priming in Parkinson's disease: A comment of Filoteo et al. (2000) and Wylie and Stout (2000). Neuropsychology, 16, 251-253.

Strayer, D. L., Drews, F. A., \& Albert, R. W. (2002). Negative priming and stimulus repetition: A reply to Neill and Joordens (2002). Attention, Perception, \& Psychophysics, 64, 861-865.

Strayer, D. L., \& Grison, S. (1999). Negative identity priming is contingent on stimulus repetition. Journal of Experimental Psychology: Human Perception and Performance, 25, 24-38.

Sturgill, D. S., \& Ferraro, F. R. (1997). Predicting negative priming: Effects of schizotypy, cognitive failures, and anxiety. Personality and Individual Differences, 23, 291-304.

Stuss, D. T., Toth, J. P., Franchi, D., Alexander, M. P., Tipper, S., \& Craik, F. I. (1999). Dissociation of attentional processes in patients with focal frontal and posterior lesions. Neuropsychologia, 37, 10051027.

Sullivan, M. P., Faust, M. E., \& Balota, D. A. (1995). Identity negative priming in older adults and individuals with dementia of the Alzheimer type. Neuropsychology, 9, 537-555.

Swerdlow, N. R., Magulae, M., Filion, D., \& Zinner, S. (1996). Visuospatial priming and latent inhibition in children and adults with Tourette's disorder. Neuropsychology, 10, 485-494.

Tipper, S. P. (1985). The negative priming effect: Inhibitory priming by ignored objects. The Quarterly Journal of Experimental Psychology Section A, 37, 571-590.

Tipper, S. P. (1991). Less attentional selectivity as a result of declining inhibition in older adults. Bulletin of the Psychonomic Society, 29, 45-47. 
Tipper, S. P. (2001). Does negative priming reflect inhibitory mechanisms? A review and integration of conflicting views. The Quarterly Journal of Experimental Psychology: Section A, 54, 321-343.

Tipper, S. P., Bourque, T. A., Anderson, S. H., \& Brehaut, J. C. (1989). Mechanisms of attention: A developmental study. Journal of Experimental Child Psychology, 48, 353-378.

Tipper, S. P., Brehaut, J. C., \& Driver, J. (1990). Selection of moving and static objects for the control of spatially directed action. Journal of Experimental Psychology: Human Perception and Performance, 16, 492-504.

Tipper, S. P., \& Cranston, M. (1985). Selective attention and priming: Inhibitory and facilitatory effects of ignored primes. The Quarterly Journal of Experimental Psychology, 37, 591-611.

Tipper, S. P., \& Driver, J. (1988). Negative priming between pictures and words in a selective attention task: Evidence for semantic processing of ignored stimuli. Memory \& Cognition, 16, 64-70.

Tipper, S. P., \& McLaren, J. (1990). Evidence for efficient visual selectivity in children. Advances in Psychology, 69, 197-210.

Tipper, S. P., Weaver, B., \& Houghton, G. (1994). Behavioural goals determine inhibitory mechanisms of selective attention. The Quarterly Journal of Experimental Psychology, 47, 809-840.

Titz, C., Behrendt, Hasselhorn, M., \& Schmuck, P. (2003). Eignet sich der Negative Priming Effekt zur reliablen Abbildung interindividueller Differenzen kognitiver Hemmung? [Is negative priming a reliable measure of individual differences in cognitive inhibition?] Zeitschrift für Differentielle und Diagnostische Psychologie, 24, 135-147.

Titz, C., Behrendt, J., Menge, U., \& Hasselhorn, M. (2008). A reassessment of negative priming within the inhibition framework of cognitive aging: There is more in it than previously believed. Experimental Aging Research, 34, 340-366.

Tse, C. S., Hutchison, K. A., \& Li, Y. (2011). Effects of contextual similarity and target-repetition proportion on negative priming in RT distributional analyses. Journal of Experimental Psychology: Human Perception and Performance, 37, 180-192.

Ungar, L., Nestor, P. G., Niznikiewicz, M. A., Wible, C. G., \& Kubicki, M. (2010). Color Stroop and negative priming in schizophrenia: An fMRI study. Psychiatry Research: NeuroImaging, 181, 24-29.

Verhaeghen, P., \& De Meersman, L. (1998). Aging and the negative priming effect: A meta-analysis. Psychology and Aging, 13, 435444.
Wagner, M., Baving, L., Berg, P., Cohen, R., \& Rockstroh, B. (2006). An ERP investigation of semantic priming, repetition priming, and negative priming in schizophrenic patients. Journal of Psychophysiology, 20, 195-211.

Watson, F. L., \& Tipper, S. P. (1997). Brief report reduced negative priming in schizotypal participants does reflect reduced cognitive inhibition. Cognitive Neuropsychiatry, 2, 67-80.

Wentura, D. (1999). Activation and inhibition of affective information: For negative priming in the evaluation task. Cognition \& Emotion, 13, 65-91.

Wong, K. F. E. (2000). Dissociative prime-probe contextual similarity effects on negative priming and repetition priming: A challenge to episodic retrieval as a unified account of negative priming. Journal of Experimental Psychology: Learning, Memory, and Cognition, 26. 1411-1422.

Wood, T. J., \& Milliken, B. (1998). Negative priming without ignoring. Psychonomic Bulletin \& Review, 5, 470-475.

World Health Organization. (2013). The ICD-10 classification of mental and behavioural disorders: Clinical descriptions and diagnostic guidelines. Geneva, Switzerland: Author.

Wright, C. I., McMullin, K., Martis, B., Fischer, H., \& Rauch, S. L. (2005). Brain correlates of negative visuospatial priming in healthy children. Psychiatry Research: NeuroImaging, 139, 41-52.

Wühr, P., \& Frings, C. (2008). A case for inhibition: Visual attention suppresses the processing of irrelevant objects. Journal of Experimental Psychology: General, 137, 116-130.

Wühr, P., \& Frings, C. (2009). Inhibition is picky: Shape difference is a necessary condition for attentional inhibition of irrelevant objects. Psychonomic Bulletin \& Review, 16, 839-844.

Wylie, S. A., \& Stout, J. C. (2002). Enhanced negative priming in Parkinson's disease. Neuropsychology, 16, 242-250.

Yeung, N., \& Cohen, J. D. (2006). The impact of cognitive deficits on conflict monitoring predictable dissociations between the errorrelated negativity and N2. Psychological Science, 17, 164-171.

Zabal, A., \& Buchner, A. (2006). Normal auditory negative priming in schizophrenic patients. The Quarterly Journal of Experimental Psychology, 59, 1224-1236.

Zimmermann, M., Stark, R., Kern, G., Laiacker, M., Kirsch, P., \& Waitl, D. (2006). Positive and negative spatial priming in schizophrenia. Journal of Clinical and Experimental Neuropsychology, 28, 706720 . 